NBER WORKING PAPER SERIES

\title{
LONG-RUN TAX INCIDENCE IN A HUMAN CAPITAL-BASED ENDOGENOUS GROWTH MODEL WITH LABOR-MARKET FRICTIONS
}

\author{
Been-Lon Chen \\ Hung-Ju Chen \\ Ping Wang \\ Working Paper 25783 \\ http://www.nber.org/papers/w25783 \\ NATIONAL BUREAU OF ECONOMIC RESEARCH \\ 1050 Massachusetts Avenue \\ Cambridge, MA 02138 \\ April 2019
}

We are grateful for valuable comments and suggestions from Marcus Berliant, Aubhik Khan, Kevin Lansing, Zheng Liu, Rody Manuelli, Milton Marquis, B. Ravikumar and John Williams, as well as participants at the Econometric Society Meeting, the Midwest Macroeconomic Conference, the Society for Advanced Economic Theory Conference, and the Society for Economic Dynamics Conference. Financial support from Academia Sinica, the National Science Council Grant (NSC 98-2911-H-001-001), the Program for Globalization Studies Grant (NTU 99R018), the Public Economics Research Center, and the Weidenbaum Center on the Economy, Government, and Public Policy is gratefully acknowledged. The views expressed herein are those of the authors and do not necessarily reflect the views of the National Bureau of Economic Research.

NBER working papers are circulated for discussion and comment purposes. They have not been peer-reviewed or been subject to the review by the NBER Board of Directors that accompanies official NBER publications.

(C) 2019 by Been-Lon Chen, Hung-Ju Chen, and Ping Wang. All rights reserved. Short sections of text, not to exceed two paragraphs, may be quoted without explicit permission provided that full credit, including $\odot$ notice, is given to the source. 
Long-Run Tax Incidence in a Human Capital-based Endogenous Growth Model with Labor-Market Frictions

Been-Lon Chen, Hung-Ju Chen, and Ping Wang

NBER Working Paper No. 25783

April 2019

JEL No. E62,H22,J24,O41

\begin{abstract}
In a second-best optimal growth setup with only factor taxes, it is in general optimal to fully replace capital by labor income taxation in the long run. We revisit this important issue by developing a human capital-based endogenous growth model with frictional labor search, allowing each firm to create multiple vacancies and each worker to determine market participation. We find that the conventional efficient bargaining condition is necessary but not sufficient for achieving constrained social optimality. We then conduct tax incidence exercises in balanced growth by calibrating to the U.S. economy with a pre-existing $20 \%$ flat tax on capital and labor income. Our quantitative results suggest that, due to a dominant channel via the interactions between vacancy creation and market participation, it is optimal to switch only partially from capital to labor taxation in a benchmark economy where human capital formation depends on both physical and human capital stocks. This main finding is robust even along the transition with time-varying factor tax rates. Moreover, our quantitative analysis under alternative setups suggest that while endogenous human capital and labor market frictions are essential for obtaining a positive optimal capital tax, endogenous leisure, nonlinear human capital accumulation and endogenous growth are not crucial.
\end{abstract}

Been-Lon Chen

Institute of Economics

Academia Sinica

128 Academia Rd. Section 2

Taipei 11529 TAIWAN

bchen@econ.sinica.edu.tw

Hung-Ju Chen

Department of Economics

National Taiwan University

Taipei

Taiwan, ROC

hjc@ntu.edu.tw
Ping Wang

Department of Economics

Washington University in St. Louis

Campus Box 1208

One Brookings Drive

St. Louis, MO 63130-4899

and NBER

pingwang@wustl.edu 


\section{Introduction}

Since the pivotal work by Chamley (1985a, 1985b, 1986) and Judd (1985, 1987), a large body of literature has been devoted to studying long-run tax incidence in optimal growth models to identify the optimal factor tax mix in a second-best world where full access to the lump-sum tax is unavailable. Because labor endowment is fixed but capital can be accumulated over time, Chamley and Judd recommended that the optimal flat factor tax scheme be implemented to fully eliminate the tax on the more elastic physical capital and to impose a tax only on the inelastic raw labor in the long run. This Chamley-Judd proposition has been revisited and extended to various economic environments and the general conclusion has been fairly robust under a benevolent nonproductive central planner using flat-rate factor taxes without other meanings of financing.

About three decades ago, the celebrated work by Lucas (1988) provided a compelling argument that human capital is a primary engine of the endogenously determined economy-wide growth rate. Because human capital augments labor, an immediate question arises: Would it be welfare-reducing to tax labor in a human capital-based endogenous growth framework? Two years later, Lucas (1990) himself addressed this question based on tax incidence exercises and provided a policy recommendation that neither physical nor human capital should be taxed and that only raw labor should be taxed. His policy recommendation has hardly been challenged within the canonical balanced-growth framework with a benevolent nonproductive central planner using only flat-rate factor taxes to finance.

In this paper, we follow this convention by reexamining the validity of the Lucasian policy recommendation in a generalized human capital-based endogenous growth economy with individuals endogenously participating in the frictional labor market. It was well-documented in the celebrated work on labor search pioneered by Diamond (1982a), Mortensen (1982) and Pissarides (1984) that informational and institutional barriers to job search, employee recruiting, and vacancy creation were substantial. In our paper, we inquire whether such frictions may influence individual decisions to generate sufficient "responsiveness" in the long run to a tax on labor income such that labor taxation becomes too distortionary to be used to fully replace capital taxation.

Our paper attempts to address this important issue that has practically valuable implications for tax reform considerations. Intuitively, by introducing labor search 
and matching friction, there are two types of distortions. First, there are matching externalities that arise from the fact that one additional job-seeker externally increases the probability that a firm will match with a worker but externally decreases the probability that job-seekers already in the market will match with a firm. ${ }^{1}$ Second, a successful match generates a surplus to be split between the worker and the firm based on a wage bargaining process rather than on a Walrasian process. The split of the surplus from a successful match is in general not efficient because firms and households ignore that the rate at which each side finds a job-match depends on the tightness of the labor market, i.e. the relative number of traders on both sides of the market. A positive capital tax can then be used to correct for distortions to labor market tightness.

Specifically, we construct a two-sector human capital-based endogenous growth framework with labor market search and matching frictions in which the worker's market participation is tied to the household's valuation of leisure. We assume that vacancy creation and maintenance as well as job search are all costly and that unfilled vacancies and active job seekers are brought together by a matching technology exhibiting constant returns. We consider "large" firms and "large" households where each firm creates and maintains multiple vacancies and each household contains a continuum of members comprising employed and nonemployed workers. The wage rate (in efficiency units) is determined based on a cooperative bargain between the matched firm and household pair. A benevolent fiscal authority finances direct transfers to households and unemployment compensation only by way of taxing factor incomes and maximizes social welfare given labor-market frictions. Notably, labor market frictions affect human capital accumulation, which is an important engine of sustainable growth. Thus, an endogenous growth model is a proper framework to evaluate the long-run effects of capital and labor income taxes and their welfare consequences.

Following the conventional tax incidence literature cited above, we begin with a long-run analysis examining the optimal factor tax mix along a balanced growth path (BGP). We generalize the benchmark study in various ways. First, we recognize that a full analysis of Ramsey taxation requires managing not only the dynamic interactions of the evolution of physical/human capital and employment (which is a state variable in search models) but also changes in household and firm values and dynamic wage bargaining. To circumvent such complication, we propose a dynamic tax incidence 
analysis under a BGP value of consumption with stationary matching and stationary bargaining. Second, we consider an alternative government instrument, in particular, the replacement ratio of unemployment compensation. In this case, we examine the optimal mix of the replacement ratio and the labor tax under the benchmark setting. Third, we reevaluate the benchmark finding by removing the channel through the labor-leisure tradeoff. Fourth, in the benchmark setup, we consider a general two-sector framework as proposed by Bond, Wang and Yip (1996) in which the accumulation of physical and human capital are both driven by physical and human capital stocks. We also consider an alternative setup with a Lucasian human capital accumulation process which is independent of physical capital.

We calibrate our economy to fit observations in the U.S. over the post-WWII period, with a pre-existing $20 \%$ tax rate being levied on both capital and labor income. This enables us to conduct tax incidence exercises along the BGP, and to draw policy recommendations based on a revenue-neutral welfare comparison of factor taxes.

Our main findings can be summarized as follows. We show that while the capital tax lowers the bargained wage rate (in efficiency units), the labor tax increases it. However, these factor taxes can generate very different effects on the wage discount that measures how much our equilibrium wage in the presence of labor market search and matching frictions is below the competitive counterpart in a frictionless Walrasian setup. Specifically, if the capital tax rate is initially too low (lower than its optimum), then an increase in the capital income tax rate accompanied by a revenue-neutral reduction in the labor tax turns out to raise the wage discount and to encourage firms to create more vacancies. This in turn raises the job finding rate and hence induces workers to more actively participate in the labor market to seek employment. Because this leads to positive effects on employment and output growth, a shift from a zero to a positive capital tax rate becomes welfare-improving, thereby yielding a policy recommendation different from that of Chamley-Judd-Lucas. Moreover, we show that the conventional efficient bargaining condition is necessary but not sufficient for achieving constrained social optimality. In addition to conventional efficient bargaining and restrictions on firms discounting at the market rate and valuing capital the same as households, efficiency requires that distorted pre-existing taxes and subsidies be removed and that the wage discount be at an optimal level aligning labor-leisureconsumption trade-off atemporally and intertemporally in our endogenously growing 
economy with labor search frictions.

By conducting factor tax incidence exercises in our benchmark economy calibrated to U.S. data, we find that, in the benchmark case with factor taxes at pre-existing rates of $(20 \%, 20 \%)$, it is optimal to only partially replace the capital tax by the labor tax: the optimal flat tax rates on capital and labor income are $16.11 \%$ and $24.09 \%$, respectively. Since the above-mentioned vacancy creation-market participation channel in the presence of labor market frictions is quantitatively significant, the optimal capital tax rate is significantly greater than zero. As a consequence, such a reform induces a $0.0389 \%$ welfare gain in consumption equivalence whereas setting the capital tax rate to zero would lead to a large welfare loss of $0.6490 \%$ in consumption equivalence. Upon various sensitivity and robustness checks, we find that it is hardly optimal to fully replace capital by labor taxation within all reasonable ranges of parameterization so long as labor-search and vacancy-creation frictions are present. The conclusion remains even when we remove the labor-leisure trade-off, or use the Lucas $(1988,1990)$ human capital accumulation process, or consider exogenous growth with endogenous human capital accumulation. In all cases, the optimal capital tax rate is still positive. On the contrary, with exogenous human capital or with a frictionless labor market, it is always optimal to fully eliminate capital taxation by taxing only labor income.

The Chamley-Judd proposition of zero capital taxation is obtained in a Walrasian economy without endogenous human capital accumulation. By allowing human capital to be determined in his endogenous growth framework, Lucas (1990) reconfirmed the Chamley-Judd proposition. By considering both endogenous human capital accumulation and labor search distortions, our paper overturns the Chamley-Judd proposition even under efficient bargains.

Our results suggest that while endogenous human capital accumulation, labor search frictions and costly vacancy creation are crucial for tax incidence to feature a positive optimal capital tax rate in the long run, the presence of labor-leisure tradeoff, the form of human capital accumulation and endogenous growth alone is not. The main takeaway of our paper is that, to achieve the highest social welfare, a proper tax reform must take into account labor market frictions and when such frictions are substantial, fully replacing capital with labor income taxation can be welfare-retarding. This finding is still robust along the transition with time-varying factor tax rates. 


\section{$\underline{\text { Related Literature }}$}

Our paper is related to the discrete-time, real-business-cycle (RBC) search literature pioneered by Merz (1995) and Andolfatto (1996). In contrast with theirs, our model considers sustained economic growth with endogenous human capital accumulation. Previously, Laing, Palivos and Wang (1995) incorporated human capital-based endogenous growth into the Mortensen-Pissarides search framework, whereas Chen, Chen and Wang (2011) introduced human capital growth into the Andolfatto-Merz RBC search framework using a pseudo central planning setup. We follow the latter strategy, allowing comprehensive labor-leisure-learning-search trade-offs. Differing from their work, our paper performs tax incidence analysis in a fully decentralized setup with a more general human capital accumulation process.

Over the past two decades, several studies have investigated the long-run growth effects of factor taxes, including King and Rebelo (1990), Stokey and Rebelo (1995), Bond, Wang and Yip (1996), and Mino (1996), under perfectly competitive setups without externalities. This literature has been extended to incorporate positive externalities, productive public capital or market imperfections, such as Guo and Lansing (1999) and Chen (2007). This strand of the literature, however, focuses exclusively on long-run growth or welfare effects of factor taxation rather than on factor tax incidence.

The closely related literature was initiated by Lucas (1990) who reexamined the Chamley-Judd proposition of tax incidence in a human capital-based endogenous growth framework. ${ }^{2}$ His primary conclusion was that the government should not tax either physical or human capital but rather tax raw labor only. This Lucasian policy recommendation was reconfirmed by Jones, Manuelli and Rossi (1993) in which only investment goods enter physical and human capital accumulation (i.e., there is no trade-off between education time and work hours). Even in a more general setup by Jones, Manuelli and Rossi (1997) that allowed both investment goods and education time to enter human capital accumulation, the Lucasian policy recommendation still remains valid under constant-returns technologies in the absence of an alternative tax on consumption.

It is noted that the Chamley-Judd proposition can be overturned under some circumstances. In an infinite-horizon endogenous growth model with human-capital formation, Chen and $\mathrm{Lu}$ (2013) showed that a positive long-run capital tax is optimal if raw labor and learning-based human capital are inseparable so that they cannot be 
taxed separately. Lu and Chen (2015) obtained a positive long-run capital tax in the model of Chamley (1986) without human capital when the government expenditure is maintained at a fixed proportion of output so that the social marginal product of capital is below its private counterpart (thus requiring a tax to correct this distortion). Reis (2011) found that capital income taxation is positive when there are two types of labor: production labor and entrepreneurial labor. Lansing (1999) and Straub and Werning (2014) both considered the Judd (1985) framework where workers are hand to mouth without saving. A positive optimal capital tax is found when the intertemporal elasticity of substitution is one (log linear) or below one. Since our setup is of the Chamley (1986) type with a representative household, it is more appropriate to compare our results with the findings in Straub and Werning who also consider Chamley's framework. In particular, Straub and Werning showed that when capital taxation is subject to an upper bound, the optimal capital tax rate is positive. In our paper, a positive optimal capital tax rate is obtained without any of such bound.

The role of search frictions played in tax incidence has been examined by Domeij (2005). In the presence of labor search distortions but the absence of human capital accumulation, Domeij (2005) applied the neoclassical growth framework to study the Ramsey taxation with the government being constrained to flat capital and labor income taxes. He showed that the result of zero capital taxation in the long run is not robust to the introduction of search frictions if Hosios' rule is not met and thus the wage bargaining is not efficient. Our quantitative results suggest that, even when Hosios' rule is met, the optimal capital tax rate is positive as long as human capital is endogenously accumulation and labor market frictions are present.

In the present paper, we follow the lead of Lucas (1990) to revisit the tax incidence issue under an endogenous growth setting with endogenous accumulation of human capital. Our departure is to consider labor-market frictions. However, when we allow for interplays between the firm's creation of vacancies and the household's decision on employment versus unemployment (referred to as the vacancy creation-market participation effect) in the presence of endogenous human capital accumulation, we find that the Chamley-Judd-Lucas proposition may now fail even under efficient bargains and even without imposing inseparability between human capital and raw labor and without assuming a government spending distortion. Our proposed new channel is of particular significance not only because of the prevalence of labor-market frictions in 
the real world but also because of the robustness of our conclusion to various alternative settings.

\section{The Model}

We consider a discrete-time model with a continuum of identical infinitely-lived large firms (of measure one), a continuum of identical infinitely-lived large households (of measure one) and a fiscal authority determining the factor tax mix.

The adoption of the large household setup is to ease unnecessary complexity involved in tracking the distribution of the employed and the unemployed, so as to eliminate the possibility of an endogenous distribution of human and physical capital stocks as a result of idiosyncratic search and matching risk in the frictional labor market. The large household consists of a continuum of members (of measure one), who are either (i) employed, by engaging in production or on-the-job learning activity, or (ii) nonemployed, by engaging in job seeking or leisure activity. We assume that households own both productive factors, capital and labor.

While the goods market is Walrasian and the capital market is perfect, the labor market exhibits search and matching frictions. In particular, a firm can create and maintain (multiple) vacancies only upon paying a vacancy creation and maintenance cost in the form of labor inputs. The household's (endogenously determined) search activity is also costly with a foregone earning cost. Unfilled vacancies and active job seekers are brought together through a Diamond (1982b) type matching technology, where each vacancy can be filled by exactly one searching worker. In our model, the flow matching rates (job finding and employee recruitment rates) are both endogenous, depending on the masses of both matching parties. In every period, filled vacancies and employed workers are separated at an exogenous rate.

The benevolent fiscal authority's behavior is simple: it taxes factor incomes at flat rates to finance direct transfers to households and unemployment compensation, given labor-market frictions. The optimal factor tax mix is to maximize social welfare by maintaining a periodically balanced budget. 


\subsection{Households}

The economy is populated with a continuum of large households of mass one, each consisting of a continuum of members of unit mass. Within each group, household members are identical; moreover, the "household head" pulls all resources for each member to achieve the same enjoyment. This assumption is common in the unitary household literature, which is made to avoid the difficulty from keeping track withinhousehold distribution over time.

In addition to the labor endowment and human capital $h_{t}$, households are assumed to own the entire stock of physical capital $k_{t}$, where the initial stocks of human and physical capital are given by, $h_{0}>0$ and $k_{0}>0$. A representative large household with a unified preference pools all resources and enjoyment from its members. In period $t$, a fraction $n_{t}$ of the members are employed and $1-n_{t}$ are nonemployed. In this setup, the unemployment rate is simply $u_{t}=1-n_{t}$. The allocation of labor is delineated in Figure 1.

Since job matches are not instantaneous, the level of employment from the household's perspective is given by the following birth-death process,

$$
n_{t+1}=(1-\psi) n_{t}+\mu_{t}\left(1-n_{t}\right)
$$

where $\psi$ denotes the (exogenous) job separation rate and $\mu_{t}$ is the (endogenous) job finding rate. That is, the change in employment $\left(n_{t+1}-n_{t}\right)$ is equal to the inflow of workers into the employment pool $\left(\mu_{t}\left(1-n_{t}\right)\right)$ net of the outflow as a result of separation $\left(\psi n_{t}\right)$.

We consider a general human capital accumulation technology proposed by Bond, Wang and Yip (1996) in which the production of incremental human capital requires both human and physical capital inputs. Denote the fraction of physical capital devoted to goods production as $s_{t}$ and that to human capital accumulation as $1-s_{t}$. The aggregate human capital of the household can thus be accumulated via learning by the employed and inputs of the market good - physical capital:

$$
h_{t+1}-h_{t}=D n_{t}\left(1-\ell_{t}\right) h_{t}+\widetilde{D}\left[\left(1-s_{t}\right) k_{t}\right]^{\gamma}\left[n_{t}\left(1-\ell_{t}\right) h_{t}\right]^{1-\gamma}
$$

where $h_{0}>0$ is exogenously given, $\gamma \in(0,1), D>0$ and $\widetilde{D} \geq 0$. When $\widetilde{D}=$ 0 (and $s=1$ ), human capital accumulation is independent of market goods. This 
linear human capital evolution process resembles that proposed by Lucas (1988): it reduces to the Lucasian setup when $n_{t}=1$. Since the accumulation of human capital depends on the employment rate $n_{t}$, it gives the flavor of on-the-job learning. The above setup implies that the unemployed cannot accumulate human capital, or, more generally, their human capital accumulation is completely offset by their human capital depreciation. ${ }^{3}$ In general, $\widetilde{D}>0$ and the accumulation of human capital requires inputs of market goods. The functional form given above implies that physical capital is not necessary for human capital accumulation as long as $D>0$. We follow Lucas (1990) assuming that education or learning activities are completely tax-exempt.

Denote the effective wage and the capital rental rates by $w_{t}$ and $r_{t}$, respectively. The labor and capital income tax rates are constant over time, denoted by $\tau_{L_{t}}$ and $\tau_{K_{t}}$, respectively. Let $c_{t}$ be household consumption and $\delta_{k}$ be the physical capital depreciation rate. In addition, denote the replacement ratio by $\bar{b}_{t}$, the per household lump-sum profit distribution by $\pi_{t}$ (to be specified below) and the per household lumpsum transfer from the government by $T_{t} .{ }^{4}$ The household faces the following budget constraint:

$$
k_{t+1}=\left(1-\tau_{L_{t}}\right) w_{t} h_{t}\left[n_{t} \ell_{t}+\left(1-n_{t}\right) \bar{b}_{t}\right]+\left[\left(1-\delta_{k}\right)+\left(1-\tau_{K_{t}}\right) r_{t} s_{t}\right] k_{t}-c_{t}+\pi_{t}+T_{t}
$$

That is, the household allocates the total wage from employed members, total unemployment compensations from unemployed members, total rentals from market capital devoted to production $\left(s_{t} k_{t}\right)$, total profits and total transfers, to consumption and gross investment.

Let $\rho>0$ be the subjective rate of time preference. The representative household's preference takes a standard time-additive form:

$$
\Omega=\sum_{t=0}^{\infty}\left(\frac{1}{1+\rho}\right)^{t} \tilde{U}\left(c_{t}, n_{t}\right)
$$

The periodic utility function is given by

$$
\begin{aligned}
\tilde{U}\left(c_{t}, n_{t}\right) & =U\left(c_{t}\right)+\left(1-n_{t}\right) \tilde{m} G(z) \\
& =U\left(c_{t}\right)+m\left(1-n_{t}\right)
\end{aligned}
$$

where $m \equiv \tilde{m} G(z), \tilde{m}>0$ measures the large household's utility weight toward valuing unemployed members' leisure, and $G$ is a function of individual leisure time $z$ facing 
each unemployed, taking a standard form with constant elasticity of intertemporal substitution $\epsilon \in(0,1): G(z)=\frac{z^{1-\epsilon^{-1}}}{1-\epsilon^{-1}}$ (e.g., see Andolfatto 1996 and many others in the macro labor literature). In this setup, what is emphasized is the extensive margin: the unemployment takes more leisure than the employed. For simplicity, we ignore the intensive margin, viewing $z$ as exogenous, so $m$ is a constant that is irrelevant for household's optimization. ${ }^{5}$ In this way, the large household's leisure is endogenous purely due to the extensive margin related to endogenous labor participation. It is noteworthy that with $\epsilon \in(0,1), G(z)<0$ and hence we expect to have $m<0$.

Let $\mathcal{H}=\left(k_{t}, h_{t}, n_{t}\right)$ denote the vector of current period state variables and $\mathcal{H}^{\prime}$ denote that of the next period state variables. Then, the household's optimization problem can be expressed in a Bellman equation form as:

$$
\Omega\left(k_{t}, h_{t}, n_{t}\right)=\max _{c_{t}, \ell_{t}, s_{t}} U\left(c_{t}\right)+m\left(1-n_{t}\right)+\frac{1}{1+\rho} \Omega\left(k_{t+1}, h_{t+1}, n_{t+1}\right)
$$

subject to constraints (1), (2), and (3).

Define conveniently effective capital-labor ratios in the nonmarket and market sectors as $q_{t}^{H}=\frac{\left(1-s_{t}\right) k_{t}}{n_{t}\left(1-\ell_{t}\right) h_{t}}$ and $q_{t}^{F}=\frac{s_{t} k_{t}}{n_{t} \ell_{t} h_{t}}$, respectively. Then the household's optimizing decisions can be summarized as follows: ${ }^{6}$

Lemma 1. (Household's Optimization) The representative large household's optimization satisfies the following first-order conditions (with respect to $\left\{c_{t}, \ell_{t}, s_{t}\right\}$ ),

$$
\begin{aligned}
U_{c} & =\frac{1}{1+\rho} \Omega_{k}\left(\mathcal{H}^{\prime}\right) \\
\Omega_{k}\left(\mathcal{H}^{\prime}\right)\left(1-\tau_{L_{t}}\right) w_{t} & =\Omega_{h}\left(\mathcal{H}^{\prime}\right)\left[D+\widetilde{D}(1-\gamma)\left(q_{t}^{H}\right)^{\gamma}\right] \\
\Omega_{k}\left(\mathcal{H}^{\prime}\right)\left(1-\tau_{K_{t}}\right) r_{t} & =\Omega_{h}\left(\mathcal{H}^{\prime}\right) \widetilde{D} \gamma\left(q_{t}^{H}\right)^{\gamma-1}
\end{aligned}
$$

together with the respective Benveniste-Scheinkman conditions (associated with $\left\{k_{t}, h_{t}, n_{t}\right\}$ ):

$$
\begin{aligned}
\Omega_{k}(\mathcal{H}) & =\frac{1}{1+\rho} \Omega_{k}\left(\mathcal{H}^{\prime}\right)\left[\left(1-\delta_{k}\right)+\left(1-\tau_{K_{t}}\right) r_{t}\right] \\
\Omega_{h}(\mathcal{H}) & =\frac{1}{1+\rho}\left(\Omega_{k}\left(\mathcal{H}^{\prime}\right)\left(1-\tau_{L_{t}}\right) w_{t}\left[n_{t} \ell_{t}+\left(1-n_{t}\right) \bar{b}_{t}\right]+\Omega_{h}\left(\mathcal{H}^{\prime}\right)\left\{1+n_{t}\left(1-\ell_{t}\right)\left[D+\widetilde{D}(1-\gamma)\left(q_{t}^{H}\right)^{\gamma}\right]\right\}\right) \\
\Omega_{n}(\mathcal{H}) & =-m+\frac{\Omega_{k}\left(\mathcal{H}^{\prime}\right)\left(1-\tau_{L_{t}}\right) w_{t} h_{t}\left(\ell_{t}-\bar{b}_{t}\right)+\Omega_{h}\left(\mathcal{H}^{\prime}\right)\left(1-\ell_{t}\right) h_{t}\left[D+\widetilde{D}(1-\gamma)\left(q_{t}^{H}\right)^{\gamma}\right]+\Omega_{n}\left(\mathcal{H}^{\prime}\right)\left(1-\psi-\mu_{t}\right)}{1+\rho}
\end{aligned}
$$

From (6) and (7), we can solve the nonmarket effective capital-labor ratio $q^{H}$ as a function of the after-tax wage-rental ratio alone:

$$
\left(q_{t}^{H}\right)^{1-\gamma}\left[D+\widetilde{D}(1-\gamma)\left(q_{t}^{H}\right)^{\gamma}\right]=\widetilde{D} \gamma \frac{\left(1-\tau_{L_{t}}\right) w_{t}}{\left(1-\tau_{K_{t}}\right) r_{t}}
$$


This positive relationship may be thought of as the relative factor input schedule to nonmarket activity: the higher the after-tax wage-rental ratio is, the greater the nonmarket effective capital-labor ratio will be. How sensitive the nonmarket effective capital-labor ratio $q_{t}^{H}$ is to changes in the after-tax wage-rental ratio depends on technology parameter $\widetilde{D}$.

\section{$2.2 \quad$ Firms}

The economy is populated by a continuum of large firms of mass one, each creating and maintaining multiple job vacancies. A representative firm produces a single final good $y_{t}$ by renting capital $k_{t}$ from households and employing labor of mass $n_{t}$ under a constant-returns-to-scale Cobb-Douglas technology,

$$
y_{t}=A\left(s_{t} k_{t}\right)^{\alpha}\left(n_{t} \ell_{t} h_{t}\right)^{1-\alpha}
$$

where $A>0$ and $\alpha \in(0,1)$.

Denoting $\eta_{t}$ as the (endogenous) recruitment rate and $v_{t}$ as (endogenous) vacancies created, we can specify the level of employment from the firm's perspective as follows:

$$
n_{t+1}=(1-\psi) n_{t}+\eta_{t} v_{t}
$$

where the change in employment is equal to the inflow of employees $\left(\eta_{t} v_{t}\right)$ net of the outflow $\left(\psi n_{t}\right)$.

To be consistent with a balanced growth equilibrium, we assume that the unit cost of creating and maintaining a vacancy is proportional to the average firm output $\bar{y}_{t}$. This setup is natural - the more production the economy has, the more firms will compete for resources and the greater the vacancy creation cost will be. Moreover, it is parsimonious - the optimization is simple because $\bar{y}_{t}$ is regarded as given to each individual firm. Furthermore, it is neutral - the base in which vacancy costs grow is not biased toward one of the two production factor inputs. Thus, the resource cost for vacancy creation and maintenance is given by $\Phi\left(v_{t}\right)=\phi \bar{y}_{t} v_{t}$, where $\phi>0$. The level of employment is the only state variable in the representative firm's optimization problem. Each unit of employment is augmented by the multiple of both work effort and human capital, $x_{t}=\ell_{t} h_{t}$. In this endogenous growth framework, both capital stocks grow unboundedly. To ensure the stationarity of the optimization problem 
(i.e., bounded firm value), we consider the firm's flow profit $\pi_{t}=A\left(s_{t} k_{t}\right)^{\alpha}\left(n_{t} x_{t}\right)^{1-\alpha}-$ $w_{t} n_{t} x_{t}-r_{t} s_{t} k_{t}-\phi \bar{y}_{t} v_{t}$ in effective units by dividing it by the "effective productivity" $\left(x_{t}\right)$ of the state variable $n_{t}$, where $x_{t}$ is taken as given by the representative firm (see Chen, Chen and Wang 2011). Given the discount rate $R_{t}$, the associated Bellman equation can then be written as:

$$
\Gamma\left(n_{t}\right)=\max _{v_{t}, k_{t}}\left\{A\left(s_{t} k_{t}\right)^{\alpha}\left(n_{t} x_{t}\right)^{1-\alpha}-w_{t} n_{t} x_{t}-r_{t} s_{t} k_{t}-\phi \bar{y}_{t} v_{t}\right\} / x_{t}+\frac{1}{1+R_{t}} \Gamma\left(n_{t+1}\right)
$$

subject to constraint (13).

Lemma 2. (Firm's Optimization) The representative firm's optimization satisfies the following first-order conditions (with respect to $\left\{v_{t}, k_{t}\right\}$ ) and the Benveniste-Scheinkman condition (associated with $\left\{n_{t}\right\}$ ):

$$
\begin{aligned}
\frac{\eta}{1+R_{t}} \Gamma_{n}\left(n_{t+1}\right) & =\phi A\left(q_{t}^{F}\right)^{\alpha} n_{t} \\
\alpha A\left(q_{t}^{F}\right)^{\alpha-1} & =r_{t} \\
\Gamma_{n}\left(n_{t}\right) & =(1-\alpha) A\left(q_{t}^{F}\right)^{\alpha}-w_{t}+\frac{1-\psi}{1+R_{t}} \Gamma_{n}\left(n_{t+1}\right)
\end{aligned}
$$

Moreover, in the interest of the owner's of the firm, the discount rate is equal to the market rental rate, i.e., $R_{t}=r_{t}$.

From (16), we can derive the market effective capital-labor ratio $q_{t}^{F}$ as a function of the capital rental rate alone:

$$
q_{t}^{F}=\left(\frac{\alpha A}{r_{t}}\right)^{\frac{1}{1-\alpha}}
$$

which is downward-sloping as expected.

\subsection{Labor Matching and Bargaining}

While the capital market is assumed to be perfect, the labor market exhibits search frictions. Following Diamond (1982), we assume pair-wise random matching in which the matching technology takes the following constant-returns form:

$$
M_{t}=B\left(1-n_{t}\right)^{\beta}\left(v_{t}\right)^{1-\beta}
$$

where $B>0$ measures the degree of matching efficacy and $\beta \in(0,1)$. 
In our model economy, the household's surplus accrued from a successful match is measured by its incremental value of supplying an additional worker $\left(\Omega_{n}\right)$ whereas the firm's surplus is measured by its incremental value of hiring an additional employee $\left(\Gamma_{n_{t}}\right)$. The representative household and the representative firm determine the effective wage rate through cooperative bargaining to maximize their joint surplus:

$$
\max _{w_{t}}\left(\Omega_{n_{t}}\right)^{\zeta}\left(\Gamma_{n_{t}}\right)^{1-\zeta}
$$

where $\zeta \in(0,1)$ denotes the bargaining share to the household. In solving this wage bargaining problem, the household-firm pair treats matching rates $\left(\mu_{t}\right.$ and $\left.\eta_{t}\right)$, the beginning-of-period level of employment $\left(n_{t}\right)$, and the market rental rate $\left(r_{t}\right)$ as given. ${ }^{7}$

Lemma 3. (Wage Bargain) The wage bargaining problem satisfies the following firstorder condition:

$$
\frac{\zeta}{w_{t}}\left(\frac{w_{t}}{\Omega_{n_{t}}} \frac{d \Omega_{n_{t}}}{d w_{t}}\right)=\frac{1-\zeta}{w_{t}}\left(-\frac{w_{t}}{\Gamma_{n_{t}}} \frac{d \Gamma_{n_{t}}}{d w_{t}}\right)
$$

With a frictional labor market and cooperative bargaining, firms will have none zero flow profit, which will be redistributed in a lump-sum fashion to households as given in (3).

\subsection{The Government}

The purpose of this paper is to study tax incidence in an economy with labor search frictions and costly vacancy creation. In order for better comparisons with the conventional tax incidence studies under canonical Walrasian settings, we regard the government as a pure tax authority, which cannot coordinate labor matching/wage bargain and cannot internalize the externality from vacancy creation via $\left\{\bar{y}_{t}\right\}$. Moreover, as in the conventional tax incidence, the government revenues are tied to the pre-existing distortionary taxes. That is, we are solving for a third best solution. The government's objective is to maximize the social welfare under a balanced budget taking matching rates as given (i.e., regard matching rates $\{\mu, \eta\}$ as given). Its budget constraint is given by, ${ }^{8}$

$$
T_{t}+w_{t} h_{t}\left(1-n_{t}\right) \bar{b}_{t}=\tau_{L t} w_{t} h_{t}\left[n_{t} \ell_{t}+\left(1-n_{t}\right) \bar{b}\right]+\tau_{K_{t}} r_{t} s_{t} k_{t}
$$


That is, the government receives wage and capital income taxes to spend on direct transfers to households and unemployment compensation. Of particular note is that the inclusion of transfers is to ensure that the government's budget is balanced in the presence of pre-existing factor taxes and unemployment compensation that fits the data observations.

Since firms' profits are redistributed to households, the social welfare is measured simply by the household's lifetime utility $\Omega$. Thus, our tax incidence problem is to determine optimal factor tax schedules $\left(\tau_{K_{t}}^{*}, \tau_{L_{t}}^{*}\right)$ by evaluating the long-run welfare outcome measured by $\Omega$, subject to all the policy functions obtained from the household's and the firm's optimization problems, the bargaining problem, and the government's budget constraint (21).

\section{Equilibrium}

A dynamic search equilibrium is a tuple of individual quantity variables, $\left\{c_{t}, \ell_{t}, v_{t}\right.$, $\left.k_{t}, h_{t}, n_{t}, y_{t}, q_{t}\right\}_{t=0}^{\infty}$, a pair of aggregate quantities $\left\{M_{t}, T_{t}\right\}_{t=0}^{\infty}$, a pair of matching rates $\left\{\mu_{t}, \eta_{t}\right\}_{t=0}^{\infty}$, and a pair of prices, $\left\{w_{t}, r_{t}\right\}_{t=0}^{\infty}$, such that: (i) all households and firms optimize; (ii) human capital and employment evolution hold, (iii) labor-market matching and wage bargaining conditions are met; (iv) the government budget is balanced; and (v) the goods market clears. A balanced growth path (BGP) is a dynamic search equilibrium along which consumption, physical and human capital, and output all grow at positive constant rates. In our model, both the market goods and the human capital investment production technologies are homogeneous of degree one in reproducible factors $(k$ and $h)$. Thus, all endogenously growing quantities $(c, k, h$ and $y$ ) must grow at a common rate, $g$, on a BGP, whereas employment $(n)$, vacancies $(v)$ and equilibrium matches $(M)$ must all be stationary. Given the common growth property, we can divide all the perpetually growing variables by $h$ to obtain stationary

ratios, $\frac{k}{h}, \frac{c}{h}$, and $\frac{y}{h}$, where the latter two ratios measure effective consumption and effective output, respectively.

Along a BGP, the labor market must satisfy the steady-state matching (Beveridge curve) relationships given by $\psi n=\mu(1-n)=\eta v=B(1-n)^{\beta}(v)^{1-\beta}$. An additional condition to the previously defined employment evolution and labor-market matching equations, (1), (13) and (19), is to require the equilibrium employment inflows from 
the household side $(\mu(1-n))$ to be equal to those from the firm side $(\eta v)$. The above relationships enable us to obtain:

Lemma 4. (Steady-State Matching) Under steady-state matching, the job finding rate $(\mu)$, the employee recruitment rate $(\eta)$ and equilibrium vacancies $(v)$ can all be solved as functions of employment $(n)$ only:

$$
\begin{gathered}
\mu(n)=\frac{\psi n}{1-n} \\
\eta(n)=B^{\frac{1}{1-\beta}} \mu(n)^{\frac{-\beta}{1-\beta}} \\
v(n)=B^{\frac{-1}{1-\beta}} \mu(n)^{\frac{\beta}{1-\beta}} \psi n
\end{gathered}
$$

While the job finding rate and equilibrium vacancies are positively related to equilibrium employment, the employee recruitment rate is negatively related to it.

Accordingly, we can also derive the labor-market tightness measure (from the firm's point of view), $\theta=v /(1-n)$, as:

$$
\theta(n)=\left[\frac{\mu(n)}{B}\right]^{\frac{1}{1-\beta}}
$$

which is positively related to the job finding rate and hence equilibrium employment.

In order to generate a BGP equilibrium, we must impose a logarithmic utility function: $U(c)=\ln c .{ }^{9}$ Using the Judd (1985) framework without endogenous human capital or labor market frictions, Lansing (1999) and Straub and Werning (2014) assume that capitalists save and workers do not save. Under a log linear utility, Lansing showed that the capital tax is nonzero, though such a finding is extended by Straub and Werning even when the intertemporal elasticity of substitution is below one. As we will see later, log utility is not a key driver of the result because in the absence of endogenous human capital or labor market frictions, capital should not be taxed at optimum even under log utility. ${ }^{10}$

Under this preference specification, households' lifetime utility is always bounded along a BGP. Moreover, $\Gamma_{n}\left(n^{\prime}\right)$ and $\Omega_{n}\left(\mathcal{H}^{\prime}\right)$ are constant along a BGP, whereas $\Omega_{k}\left(\mathcal{H}^{\prime}\right)$ and $\Omega_{h}\left(\mathcal{H}^{\prime}\right)$ are decreasing at rate $g$. Using (6), (8), and (9), in the Appendix we derived a standard Keynes-Ramsey relationship governing consumption growth and an intertemporal optimization condition governing human capital accumulation. Following the argument in Bond, Wang and Yip (1996), we assume throughout the paper the following condition to ensure nondegenerate balanced growth: 
Condition G. (Nondegenerate Growth) inf $\{r\}>\frac{\delta_{k}+\rho}{1-\tau_{K}}$.

This condition basically limits the range of factor price frontier. ${ }^{11}$

We can use human capital evolution (2) to relate learning effort to the nonmarket effective capital-labor ratio, employment and the balanced growth rate:

$$
1-\ell=\frac{g}{n\left[D+\widetilde{D}\left(q^{H}\right)^{\gamma}\right]}
$$

Further define unit wage income as $S_{w}=\left(1-\tau_{L}\right)\left[1+\frac{(1-n) \bar{b}}{n \ell}\right]$ and unit rental income as $S_{r}=\left[\left(1-\tau_{K}\right) r-\frac{g+\delta_{k}}{s}\right]$. From the definition of $\pi$ and (16), we have derived the flow profit redistribution to each household in effective units in the Appendix. Moreover, from (3), the definition of $q^{F}$ and the flow profit redistribution given above, we have derived effective consumption along a BGP in the Appendix.

To solve the wage bargaining problem, we first note that the household-firm pair in the bargaining game must take $\{\mu, \eta, n, r\}$ as given. From (18), $q^{F}$ must also be regarded as predetermined. Using (11) and the intertemporal optimization condition governing human capital accumulatio in the Appendix, we can express both the nonmarket effective capital-labor ratio and the balanced growth rate as increasing functions of the bargained wage only: $q^{H}=q^{H}(w)$ and $g=g(w)$. Intuitively, while it is clear that a higher wage and hence a higher wage-rental ratio (given $r$ ) leads to a higher non-market effective capital-output ratio, the latter in turn raises the BGP human capital accumulation rate. Combining the Keynes-Ramsey relationship in the Appendix and $(26)$ yields $\ell(w)=1-\frac{(1-\gamma) g(w)}{n}\left[\frac{(1+\rho) g(w)+\rho}{n+(1-n) b}-\gamma D\right]^{-1}$.

The bargained wage serves as an incentive to encourage households, on the one hand, to devote more effort to market activity, while, on the other hand, accumulating more human capital. When the long-run human capital accumulation effect dominates (as it will in the calibrated economy), it is expected that an increase in the bargained wage will reduce work effort. By the definitions of $q^{F}$ and $q^{H}$, we have:

$$
\frac{q^{F}}{q^{H}(w)}=\frac{s}{1-s} \frac{1-\ell(w)}{\ell(w)}
$$

which can then be used to derive $s=s(w)$ as a decreasing function of the bargained wage. Intuitively, a higher bargained wage raises the learning effort $(1-\ell)$ and, by capital-labor complementarity, results in a larger fraction of capital being devoted to human capital accumulation (i.e., a higher $1-s$ ). 
Endowed with the functions $q^{H}(w), g(w), \ell(w)$ and $s(w)$ given above, we are now ready to determine the equilibrium wage. Substituting (5) and (7) into (10), we can write the household's surplus accrued from a successful match as follows:

$$
\Omega_{n}=\frac{1+\rho}{\rho+\psi+\mu_{t}}\left[\left(1-\tau_{L_{t}}\right)\left(1-\bar{b}_{t}\right) \frac{w_{t}}{c_{t} / h_{t}}-m\right]
$$

where from (50) $\frac{c_{t}}{h_{t}}$ is increasing in $w_{t}$ but less than proportionally, implying that the household's surplus is increasing in $w_{t}$.

It is informative to compute the wage discount that measures how much the bargained wage is below its competitive counterpart (i.e., the marginal product of labor, $M P L)$ :

$$
\Delta_{t} \equiv \frac{M P L_{t}-w_{t}}{M P L_{t}}=1-\frac{w_{t}}{(1-\alpha) A\left(q_{t}^{F}\right)^{\alpha}}
$$

Straightforward differentiation of the surplus accrued by each party leads to $-\frac{w_{t}}{\Gamma_{n}} \frac{d \Gamma_{n}}{d w_{t}}=$ $\frac{1-\Delta_{t}}{\Delta_{t}}$ and $\frac{w_{t}}{\Omega_{n}} \frac{d \Omega_{n}}{d w_{t}}=\frac{S_{r} q_{t}^{F}+\left(\pi_{t}+T_{t}\right) /\left(n_{t} \ell_{t} h_{t}\right)}{S_{w} w_{t}+S_{r} q_{t}^{F}+\left(\pi_{t}+T_{t}\right) /\left(n \ell_{t} h_{t}\right)}$. While the former is decreasing in the wage discount $\Delta$ and hence increasing in $w$, the latter is decreasing in $w$. Thus, we can manipulate (20) to obtain (see Appendix):

Lemma 5. (Wage Determination) The bargained wage is characterized by,

$$
M B_{w}=\frac{\zeta}{w_{t}-m \frac{\left(S_{w} w_{t}+S_{r} q_{t}^{F}\right) n_{t} \ell_{t}+\left(\pi_{t}+T_{t}\right) / h v}{\left(1-\tau_{L_{t}}\right)\left(1-\bar{b}_{t}\right)}} \frac{S_{r} q_{t}^{F} n_{t} \ell_{t}+\frac{\pi_{t}+T_{t}}{h_{t}}}{\left(S_{w} w_{t}+S_{r} q_{t}^{F}\right) n_{t} \ell_{t}+\frac{\pi_{t}+T_{t}}{h_{t}}}=\frac{1-\zeta}{(1-\alpha) A\left(q_{t}^{F}\right)^{\alpha}-w_{t}}=M C_{w}
$$

where $M B_{w}$ is decreasing but $M C_{w}$ is increasing in $w$.

The determination of bargained wage is illustrated in the top panel of Figure 2, when the marginal benefit from the household's point of view $\left(M B_{w}\right)$ equals the marginal cost from the firm's point of view $\left(M C_{w}\right)$. We are now prepared to characterize the effects of factor taxes on bargained wages, given $\left\{\mu_{t}, \eta_{t}, n_{t}, r_{t}\right\}$ and hence the effective capital-labor ratio $q_{t}^{F}$ (refer to (18)).

An increase in $\tau_{K_{t}}$ has a direct negative effect via the after-tax rental on the unit rental income $\left(S_{r}\right)$, which decreases the household's marginal benefit and leads to a downward shift in the $M B_{w}$ locus. ${ }^{12}$ There is also an indirect effect via the laborleisure trade-off (which would have vanished if $m=0$ ), which tends to shift the $M B_{w}$ locus upward (recall that $m<0$ ). Similarly, there are two direct effects via the aftertax wage of higher labor taxation $\tau_{L_{t}}$ : one is to reduce $S_{w}$ and thus shift the $M B_{w}$ 
locus up and another is to suppress $M B_{w}$ via the extensive margin of leisure. The indirect effect via leisure is generally ambiguous (one via $S_{w}$ and another via the net opportunity cost of staying unemployed, $\left.\left(1-\tau_{L_{t}}\right)\left(1-\bar{b}_{t}\right)\right)$. Since $q_{t}^{F}$ is taken as given for a particular value of $r_{t}$, it is clear that the $M C_{w}$ locus will not respond to changes in factor tax rates. As a result, the marginal benefit from the household's point of view is decreasing in the capital tax rate, whereas it is increasing in the labor tax rate when the marginal valuation of leisure is sufficiently low (such that the magnitude of $m$ is sufficiently small).

Moreover, by similar arguments, we can show that the marginal benefit from the household's point of view is increasing in employment when the marginal valuation of leisure is sufficiently low. We arrive at:

Proposition 1. (Wage Offer) There is a unique bargained wage $w\left(n_{t} ; \tau_{K_{t}}, \tau_{L_{t}}\right)$ solving (30), which possesses the following properties:

(i) it is decreasing in the capital tax rate $\left(\tau_{K_{t}}\right)$ unambiguously, but increasing in the labor tax rate $\left(\tau_{L_{t}}\right)$ if the marginal valuation of leisure is sufficiently low;

(ii) it is increasing in employment $\left(n_{t}\right)$ if the marginal valuation of leisure is sufficiently low ( $m$ sufficiently small in magnitude).

Intuitively, a higher capital tax discourages capital accumulation, thus lowering the marginal product of labor and the bargained wage. On the contrary, a higher labor tax discourages household's participation in the labor market, thereby requiring a high wage to induce the participation. We can also plot the relationship between the wage discount and the wage rate, which is downward-sloping based on the expression in (29) above (see the bottom panel of Figure 2).

Once the bargained wage is determined (see $w_{0}$ in Figure 2), we can then solve the associated wage discount using (29). Notice that this wage discount schedule only depends on the market effective capital-labor ratio $q_{t}^{F}$. From (11), (18), (27), and the Keynes-Ramsey relationship governing consumption growth, we can see that for each $w_{t}$, the pre-tax real rental rate $r_{t}$ is increasing in the capital tax rate but decreasing in the labor tax rate as long as the labor cost share in the goods sector $(1-\alpha)$ is sufficiently high:

Condition LC. (Goods-Sector Labor Cost Share) $1-\alpha>\sup _{w}\left\{\left(1-s\left(w_{t}\right)\right) s\left(w_{t}\right)\right\}$. 
Under this (sufficient but not necessary) condition on labor cost shares, by raising the pre-tax real rental rate and hence reducing $q_{t}^{F}$, an increase in $\tau_{K_{t}}$ shifts the wage discount schedule down; on the contrary, an increase in $\tau_{L_{t}}$ raises $q_{t}^{F}$ and shifts the wage discount schedule up.

We then obtain the following:

Proposition 2. (Wage Discount Function) Under Condition $L C$, the wage discount function possesses the following properties:

(i) its schedule $\Delta\left(w_{t}\right)$ is a decreasing function of the bargained wage $\left(w_{t}\right)$, shifting down in response to a higher capital tax rate $\left(\tau_{K_{t}}\right)$ and up in response to a higher labor tax rate $\left(\tau_{L_{t}}\right)$;

(iii) its value $\Delta_{t}$ is increasing in the capital tax rate and decreasing in the labor tax rate when the bargained wage is sufficiently responsive to factor tax changes.

In response to a higher capital tax, the bargained wage is lower, the pre-tax rental is higher and the wage discount schedule shifts downward. When the bargained wage is sufficiently responsive, the wage discount is higher. Similarly, with a sufficiently responsive bargained wage, the wage discount is lower in response to a higher labor tax. Such negative relationships between the bargained wage and the wage discount are intuitive and natural, which are supported by our calibration analysis.

Furthermore, we can manipulate (15), (16), (17) and (23) to obtain an expression that relates employment and capital rental to the wage rate:

$$
w_{t}=\frac{r_{t} q_{t}^{F}}{\alpha}\left[(1-\alpha)-\frac{\left(r_{t}+\psi\right) \phi}{\eta\left(n_{t}\right)} n_{t}\right]
$$

Using the capital rental function derived above $r\left(g_{t} ; \tau_{K t}, \tau_{L_{t}}\right)$ and the wage function $w\left(n_{t} ; \tau_{K_{t}}, \tau_{L_{t}}\right)$ given in Proposition 1, we can then express (31) as a relationship in $\left(n_{t}, g_{t}\right)$. This relationship summarizes a firm's efficiency condition that governs capital demand, labor demand and vacancy creation, with steady-state matching and bargained wage conditions embedded, which is referred to as the equilibrium firm efficiency $(F E)$ relationship. Note that $r_{t} q_{t}^{F}$ is decreasing in $r_{t}$ whereas $\eta\left(n_{t}\right)$ is decreasing in $n_{t}$, so the right-hand side of (31) is decreasing in both $r_{t}$ and $n_{t}$. From (47), $r_{t}$ is increasing in $g_{t}$, whereas from Proposition $1, w_{t}$ is increasing in $n_{t}$ when the marginal valuation of leisure is sufficiently low. Thus it is clear that the $F E$ locus is downward 
sloping. Moreover, a higher tax on capital income unambiguously raises the pre-tax capital rental and reduces the barged wage whereas a higher tax on labor income generates opposite effects. Thus, when the own price effect via the after-tax wage-rental ratio dominates, an increase in either tax rate shifts the $F E$ locus downward (see Figure 3).

Similarly, we can substitute the capital rental function $r\left(g_{t} ; \tau_{K_{t}}, \tau_{L_{t}}\right)$ and the wage function $w\left(n_{t} ; \tau_{K_{t}}, \tau_{L_{t}}\right)$ into (11) and use it with the intertemporal optimization condition to obtain another balanced growth relationship in $\left(n_{t}, g_{t}\right)$, which is referred to as the optimized human capital accumulation $(H A)$ relationship. It is obvious that, with $r_{t}$ increasing in $g_{t}$ and $w_{t}$ increasing in $n_{t}$, the $H A$ locus is upward sloping. Recall that a higher capital tax or a lower labor tax increases the pre-tax capital rental and reduces the bargained wage. Notably, the intertemporal optimization condition governing human capital accumulation indicates that factor taxes only affect this $H A$ locus via the nonmarket effective capital-labor ratio $q_{t}^{H}$ that is an increasing function of the after-tax wage-rental ratio. Because an increase in the capital tax rate reduces the after-tax rental $\left(1-\tau_{K_{t}}\right) r_{t}$ and an increase in the labor tax rate decreases the after-tax wage $\left(1-\tau_{L_{t}}\right) w_{t}$, it is easily seen that, when the own price effect dominates, a higher capital tax tends to raise $q_{t}^{H}$ whereas a higher labor tax tends to lower it. Thus, while a higher capital tax shifts the $H A$ locus upward, a higher labor tax shifts the locus downward (see Figure 3). We should note that the nonmarket effective capital-labor ratio will not be responsive to changes in the after-tax wage-rental ratio when the technology parameter $\widetilde{D}$ is small. This implies that the factor tax effects on the $H A$ locus become negligible as $\widetilde{D}$ becomes sufficiently small.

To characterize the effects of factor income taxes on employment and growth, we further impose a condition on factor price responses:

Condition FP. (Dominant Own Price Effects of Factor Taxes) Each factor price and after-tax factor price are more responsive to its own factor tax rate.

From (11), it is clearly seen that Condition FP holds true if the technology parameter $\widetilde{D}$ is sufficiently small. ${ }^{13}$ We then have:

Proposition 3. (Employment and Growth) Under Conditions LC and FP, the balanced growth equilibrium possesses the following properties:

(i) an increase in either the capital tax rate $\left(\tau_{K}\right)$ or the labor tax rate $\left(\tau_{L}\right)$ shifts the 
$F E$ locus down, but an increase in the capital tax rate $\left(\tau_{K}\right)$ shifts the $H A$ locus up whereas an increase in the labor tax rate $\left(\tau_{L}\right)$ shifts the $H A$ locus down;

(ii) when the technology parameter $\widetilde{D}$ is sufficiently small such that the $H A$ locus is not too responsive to changes in the factor taxes, an increase in either factor tax reduces employment and growth.

The results depicted in Figure 3 are under own price dominance (Condition FP) and

sufficiently small $\widetilde{D}$. Based on the discussion above, we can easily show that along the balanced growth path, a higher capital tax induces physical capital to be allocated away from the market sector (thus decreasing the effective capital-labor ratio in the market sector), a higher labor tax encourages human capital to be allocated to nonmarket activity (thus lowering the effective capital-labor ratio in the nonmarket sector). Just how capital taxation may affect the effective capital-labor ratio in the nonmarket sector or how labor taxation may affect the effective capital-labor ratio in the market sector will depend on both factor substitution and other indirect effects, which cannot be pinned down analytically in a clear-cut manner.

\section{Efficiency}

In this section, we turn to efficiency issues by considering a quasi-social planner's problem where the central planner takes $\bar{y}_{t}$ as given (as the vacancy-creation externality is purely for providing unbiased support for endogenous growth, which is not present in the standard efficient bargain literature).

The quasi-social planner can allocate consumption, labor, capital and vacancy under its budget constraint given by (21), as well as coordinate labor matching to achieve efficiency (in the second best sense due to its ignorance of the vacancy-creation externality). To save the space, we express the quasi-social planner's problem and the first-order conditions in the Appendix.

The main task here is to derive conditions for efficiency by setting the decentralized solution to be the same as the centralized solution. Recall that in order to generate a BGP equilibrium, we impose $U(c)=\ln c$ and, along a BGP, $\Gamma_{n}\left(n^{\prime}\right)$ and $\Omega_{n}\left(\mathcal{H}^{\prime}\right)$ are constant whereas $\Omega_{k}\left(\mathcal{H}^{\prime}\right)$ and $\Omega_{h}\left(\mathcal{H}^{\prime}\right)$ are decreasing at rate $g$. We shall use these properties of the value functions in our analysis below. In particular, as shown in 
the Appendix, we can combine the decentralized solution with the cooperative Nash wage bargain expression to yield an expression for a labor-leisure-consumption tradeoff under the decentralized solution. Moreover, we also obtain counterpart of this labor-leisure-consumption trade-off under the centralized solution.

Then, by comparing the decentralized and centralized solutions, namely (51) and (55) in the Appendix, we can identify four conditions. Moreover, to ensure the laborleisure-consumption trade-off under decentralization and centralization to be identical, in the Appendix we have established equivalence between the decentralized laborleisure-consumption trade-off and the counterpart of this labor-leisure-consumption trade-off under the centralized solution and obtained four conditions. We therefore arrive at:

Proposition 4. (Efficiency) By taking the vacancy creation externality $\left(\bar{y}_{t}\right)$ as given in both decentralized and centralized problems, the decentralized dynamic search equilibrium along the balanced growth path achieves second-best, solving the quasi-social planner problem, under the following conditions:

(i) (discounting and valuation of capital) firms discount at the market rental rate $\left(R_{t}=r_{t}\right)$ and value capital in the same manner as the quasi-social planner $\left(\Omega_{k}\left(\mathcal{H}^{\prime}\right)=\Lambda_{k}\left(\mathcal{H}^{\prime}\right)\right)$;

(ii) (removal of distortionary factor taxes and subsidies) $\tau_{K_{t}}=\tau_{L_{t}}=\bar{b}_{t}=0$;

(iii) (efficient bargains) $\zeta=\beta$;

(iv) (efficient wage discount): wage discount is set at $\Delta_{t}=\Delta_{t}^{*}=\frac{\left(\rho+\psi+\beta \mu_{t}\right) \phi n_{t} \ell_{t}}{(1-\alpha) \eta_{t}}$.

That is, the Hosios' rule, based on labor-market matching and bargaining efficiency and equating matching elasticities to the respective bargaining shares $\zeta=\beta$, is necessary but not sufficient for efficiency. With endogenous human capital accumulation and endogenous labor-leisure-consumption trade-off atemporally and intertemporally, we need additional conditions to achieve efficiency. The efficient wage discount condition may be understood as follows. Intuitively, each firm sets a level of discount such that the bargaining outcome exactly balances the household's incentives between working and consuming the fruit of wage payment and taking the leisure by not participating in the labor market. In response to an increase in the vacancy creation cost (higher $\phi$ ), 
it would thus require larger wage discount (higher $\Delta^{*}$ ) in order to compensate firms while maintaining workers indifferent. While better matching to workers (higher $\mu$ ) requires greater wage discount to compensate firms, better matching to firms (higher $\eta)$ have the opposite effects. Moreover, since a rising job separation rate $(\psi)$ reduces firm's surplus by more than household's, it requires the wage discount to increase. We must note that in the case when the vacancy creation cost is zero $\phi=0$, or when the matching to firms is instantaneous $\eta=\infty$, then $\Delta=0$ and Condition (iv) is not needed.

Notably, both the first set of conditions regarding discounting and valuation of capital and the third entailing the Hosios' rule are standard in the literature, which will be imposed throughout the remainder of the paper. Unfortunately, the second set of conditions involves removal of distortionary factor taxes and subsidies, which cannot be imposed in our analysis, because the tax incidence is the primary purpose of our paper. Specifically, in the tax incidence literature (e.g., Judd, 1985; Chamley, 1986; Lucas, 1990), it is standard to study what the optimal factor income tax mix is to finance a positive level of government expenditure.

As a consequence, we shall not impose an efficient wage discount as it is a property derived in the absence of any pre-existing distortionary factor taxes or subsidies. Thus, in the calibrated economy below, the optimality is more precisely referred to as to achieve the third best (by not correcting the vacancy creation externality and by allowing for pre-existing distortionary factor taxes and subsidies). We will establish quantitatively in Section 6 below that, no matter whether Hosios' rule is met or not, it is optimal to tax capital.

\section{Dynamic Taxation}

In this section, we examine dynamic taxation. Notably, a full analysis of Ramsey taxation requires managing not only the evolution of the state vector $\left(k_{t}, h_{t}, n_{t}, t\right)$ but also changes in household and firm values, $\Omega_{n_{t}}\left(k_{t}, h_{t}, n_{t}, t\right)$ and $\Gamma_{n_{t}}\left(k_{t}, h_{t}, n_{t}, t\right)$, as well as dynamic wage bargaining. The dynamic interactions are complicated, so a full analysis is next to impossible. To circumvent this problem, we focus on studying dynamic taxation under a BGP value of consumption with stationary matching and stationary bargaining. More specifically, we consider dynamic paths of factor tax rates 
starting from their pre-existing levels and asymptotically approaching to their optimal BGP levels $\left(\tau_{K}^{*}, \tau_{L}^{*}\right)$, while maintaining the replacement ratio at its pre-existing level $\bar{b}_{t}=\bar{b}$. We shall return to examining optimal replacement ratio in the extension section.

While we will reconfirm numerically that such a simplification is innocuous, we would like to stress now that the benefit to consider this simplified structure is to isolate the long-run growth and matching effects via $(g, n)$ from short-run transition analysis. In particular, when $g$ and $n$ are at their BGP levels, we can derive from (22), (23), (24) and (25) that $\mu, \eta, v$, and $\theta$ are all constant. This enables us to study dynamic taxation in a parsimonious manner.

In the Appendix, we show that, both factor prices can be expressed as functions of the capital tax alone (independent of the labor tax rate and the replacement ratio):

$$
\begin{aligned}
r\left(\tau_{K t}\right) & =\left[g(1+\rho)+\delta_{k}+\rho\right] /\left(1-\tau_{K t}\right) \\
w\left(\tau_{K t}\right) & =A^{\frac{1}{1-\alpha}}\left(\alpha / r\left(\tau_{K t}\right)\right)^{\frac{\alpha}{1-\alpha}}\left[1-\alpha-\left(r\left(\tau_{K t}\right)+\psi\right) \phi n / \eta(n)\right]
\end{aligned}
$$

We further show that capital rental is increasing in the capital tax rate at an increasing rate $\left(r^{\prime}\left(\tau_{K t}\right)>0, r^{\prime \prime}\left(\tau_{K t}\right)>0\right)$ and the after-tax capital rental is decreasing in the capital tax rate. As a result of factor substitution, effective wage is shown to be decreasing in the capital tax rate. When the direct production cost effect dominates the labor market friction effect (the last term in the square bracket of the effective wage expression), effective wage is strictly concave in the capital tax rate. As shown in the Appendix, we can also utilize (18), (48) and (26) to obtain $q_{t}^{F}=q^{F}\left(\tau_{K t}\right), q_{t}^{H}=q^{H}\left(\bar{b}_{t}\right)$ and $\ell_{t}=\ell\left(\bar{b}_{t}\right)$, with $\frac{\partial q_{t}^{F}}{\partial \tau_{K t}}<0, \frac{\partial q_{t}^{H}}{\partial \bar{b}_{t}}<0$ and $\frac{\partial \ell_{t}}{\partial \bar{b}_{t}}<0$.

Since the effective capital-labor ratio in the nonmarket sector is a function of the replacement ratio alone, equation (11) can be rewritten as:

$$
\bar{b}_{t}=f\left(\tau_{K t}, \tau_{L t}\right)
$$

This is referred to as an iso-replacement ratio (IR) locus, As shown in the Appendix, $\frac{\partial \bar{b}_{t}}{\partial \tau_{L t}}>0$ and $\frac{\partial \bar{b}_{t}}{\partial \tau_{K t}}>0$, so time varying factor tax rates are negatively related along each IR locus. That is, to maintain a constant replacement ratio, there is a trade-off between the two required factor tax rates. Moreover, under the condition mentioned above, the IR locus is concave. 
Recall that the dynamic paths of factor tax rates satisfy: (i) $\left(\tau_{K_{0}}, \tau_{L_{0}}\right)$ are at their pre-existing levels; (ii) $\lim _{t \rightarrow \infty} \tau_{K_{t}}=\tau_{K}^{*}$ and $\lim _{t \rightarrow \infty} \tau_{L_{t}}=\tau_{L}^{*}$; and, (iii) $\left(\tau_{K t}, \tau_{L t}\right.$ ) satisfy the IR locus with $\bar{b}_{t}=\bar{b}$. We may thus express the two factor tax schedules as follows:

$$
\begin{aligned}
\tau_{K_{t}}-\tau_{K}^{*} & =A_{K} e^{-a_{K}(t) \cdot t} \\
\tau_{L_{t}}-\tau_{L}^{*} & =-A_{L} e^{-a_{L}(t) \cdot t}
\end{aligned}
$$

where $A_{i}$ and $a_{i}$ are all positive for $i=K, L$, the initial tax rates are $\tau_{K_{0}}=\tau_{K}^{*}+A_{K}$ and $\tau_{L_{0}}=\tau_{L}^{*}-A_{L}$ with $\left(A_{K}, A_{L}\right)$ satisfying the IR locus, and the transition speeds are captured by $\left(a_{K}(t), a_{L}(t)\right)$ which must satisfy the IR locus for all $t$.

Define $\Theta(\bar{b})=\left(q^{H}(\bar{b})\right)^{1-\gamma}\left[D+\widetilde{D}(1-\gamma)\left(q^{H}(\bar{b})\right)^{\gamma}\right] \frac{g(1+\rho)+\delta_{k}+\rho}{\widetilde{D} \gamma}$. We show in the Appendix that

$$
A_{L}\left(A_{K}\right)=-1+\tau_{L}^{*}+\frac{\left(\alpha^{\alpha} A\right)^{\frac{-1}{1-\alpha}}\left[\frac{g(1+\rho)+\delta_{k}+\rho}{1-\tau_{K}^{*}-A_{K}}\right]^{\frac{\alpha}{1-\alpha}} \Theta(\bar{b})}{1-\alpha-\frac{\phi n}{\eta}\left[\frac{g(1+\rho)+\delta_{k}+\rho}{1-\tau_{K}^{*}-A_{K}}+\psi\right]}
$$

which depends positively on $A_{K}$ when the capital income share is not too high such that $\alpha<\min \left\{\frac{1}{2}, 1-\frac{\psi \phi n}{\eta}\right\}$. Thus the two initial tax rates are negatively related, which is easily understood because the IR locus is downward sloping. Moreover, the speed of labor taxation $a_{L}(t)$ is governed by,

$$
\begin{gathered}
\ln \left[1-\tau_{L}^{*}+A_{L}\left(A_{K}\right) e^{-a_{L}(t) \cdot t}\right]=\ln \left(\alpha^{\alpha} A\right)^{\frac{-1}{1-\alpha}} \Theta(\bar{b}) \\
+\frac{\alpha}{1-\alpha} \ln \frac{g(1+\rho)+\delta_{k}+\rho}{1-\tau_{K}^{*}-A_{K} e^{-a_{K}(t) \cdot t}} \\
-\ln \left\{1-\alpha-\frac{\phi n}{\eta}\left[\frac{g(1+\rho)+\delta_{k}+\rho}{1-\tau_{K}^{*}-A_{K} e^{-a_{K}(t) \cdot t}}+\psi\right]\right\}
\end{gathered}
$$

By expressing $a_{L}(t)$ as a function of $\left(a_{K}(t), A_{K}\right)$, it is straightforward to show that $\frac{d a_{L}}{d a_{K}}>0$. The effect of the gap between the initial and the asymptotic levels of the capital tax rate $\left(A_{K}\right)$ is, however, complicated. On the one hand, it affects the gap between the initial and the asymptotic levels of the labor tax rate $\left(A_{L}\right)$ as given in (33), which requires the speed of adjustment in the labor tax rate to be faster in order for convergence toward its long-run level. On the other hand, there is an opposite effect via the IR locus, thus leading to an ambiguous net effect.

With the above characterization of the two factor tax schedules along the transition, we are now ready to set up the steps toward welfare evaluation. To begin, we note 
from (2) that once $g$ and $n$ are at their BGP levels, the growth rate of $h_{t}$ is constant as well. We may thus focus on analyzing the transition of effective consumption, $\frac{c_{t}}{h_{t}}$, when evaluating welfare. To do so, we show in the Appendix that the fraction of capital devoted to goods production can be written as a function of the capital tax rate and the replacement ratio: $s_{t}=s\left(\tau_{K t}, \bar{b}\right)$. Moreover, we can express unit wage income

and unit rental income as $S_{w t}=S_{w}\left(\tau_{L t}, \bar{b}\right)$ and $S_{r t}=S_{r}\left(\tau_{K t}, \bar{b}\right)$, and the effective lump-sum tax rebate as $\frac{T_{t}}{h_{t}}\left(\tau_{K t}, \tau_{L t}, \bar{b}\right)$. We may thus rewrite (50) as:

$$
\begin{aligned}
\frac{c_{t}}{h_{t}}\left(\tau_{K t}, \tau_{L t}, \bar{b}\right)= & \left\{A\left[q^{F}\left(\tau_{K t}\right)\right]^{\alpha}[(1-\alpha)-\phi v]+S_{r}\left(\tau_{K t}, \bar{b}\right) q^{F}\left(\tau_{K t}\right)\right. \\
& \left.-\left[1-S_{w}\left(\tau_{L t}, \bar{b}\right)\right] w\left(\tau_{K t}\right)\right\} n \ell+\frac{T_{t}}{h_{t}}\left(\tau_{K t}, \tau_{L t}, \bar{b}\right)
\end{aligned}
$$

In the Appendix, we show that, when the effective lump-sum tax rebate effect is neglected, a higher labor tax rate suppresses effective consumption, whereas the capital tax rate also has a negative effect if its impact via the bargained wage rate is not too large.

\section{Numerical Analysis}

We now turn to calibrating our benchmark model. We then conduct comparative-static exercises quantitatively, particularly focusing on the balanced growth effects of the two factor tax rates. We then perform tax incidence exercises and derive the optimal factor tax mix numerically. Finally, we perform sensitivity analysis to examine the robustness of our numerical results.

\subsection{Calibration}

We calibrate parameter values to match the U.S. quarterly data during the post-WWII period. We set the quarterly per capita real GDP growth rate to $g=0.45 \%$ and the quarterly depreciation rate of capital to 0.01 to match the annual per capita real GDP growth rate of $1.8 \%$ and the annual depreciation rate of capital in the range of $3-8 \%$, respectively. With an annual time preference rate of $5 \%$, we set our quarterly rate of time preference to 0.0125 . The output elasticity of capital is set at the average capital income share $\alpha=0.28$. Based on the observation and the factor tax incidence exercises conducted by Judd (1985) and many others, we set the pre-existing flat tax 
rates: $\tau_{K}=0.2$ and $\tau_{L}=0.2 .{ }^{14}$ The capital rental rate can then be calibrated by using (47): $r=0.03382$, which implies a capital-output ratio $k / y=\frac{\alpha}{r}=8.279$, close to the observed value. As argued by Kendrick (1976), human capital is as large as physical capital. We thus set the benchmark value of the physical to human capital ratio at $k / h=1$.

The ratio of unemployment compensation to the market wage $(\bar{b})$ in the benchmark case is set to 0.42, in line with Shimer (2005) and Hall (2005). Also based on Shimer (2005), the monthly separation rate is given as 0.034 and the monthly job finding rate as 0.45 . These enable us to compute the quarterly separation rate $\psi=1-(1-0.034)^{3}=$ 0.0986 and the quarterly job finding rate $\mu=1-(1-0.45)^{3}=0.8336$. From the Beveridge curve, we can compute: $n=\frac{\mu}{\mu+\psi}=0.8943$. By following Shimer (2005) to normalize the vacancy-searching worker ratio $\left(\frac{v}{u}\right)$ as one, we can utilize the Beveridge curve and (22) to calibrate $\eta=B=0.834$ and use (24) to obtain $v=\frac{\psi n}{\eta}=0.1057$. Following Blanchard and Diamond (1990), we set the benchmark value of the worker elasticity of matching as $\beta=0.4$. Because the Hosios' rule is a necessary condition for efficient bargains, we impose $\zeta=\beta=0.4$.

Next, we follow Andolfatto (1995), setting $\epsilon=0.5$. In Andolfatto, the marginal utility from leisure accrued by the unemployed is $\tilde{m}=1.37$. In addition, we can have a quick accounting of households' time use to obtain a reasonable allocation of time for work, learning and leisure at $20 \%, 8 \%$ and $72 \%$, respectively. These together with the calibrated value of $n$ yield total units of time facing the large household $N=n \ell+n(1-\ell)+(1-n) z=3.167$, equilibrium work effort $\ell=0.725$ and equilibrium leisure $z=21.5$ (i.e., at the household level, the fractions of work, learning and leisure time are $\frac{n \ell}{N}, \frac{n(1-\ell)}{N}$ and $\frac{(1-n) z}{N}$, respectively, which match the respective targets). ${ }^{15}$ Thus, $m=-1.37 \cdot(21.5)^{-1}=-0.064$.

Moreover, from the definitions of $q^{F}$ and $q^{H}$, we can write:

$$
\begin{aligned}
q^{F} & =\frac{s k}{n \ell h}=\frac{s}{0.8943 \cdot 0.725}=q^{F}(s) \\
q^{H} & =\frac{(1-s) k}{n(1-\ell) h}=\frac{1-s}{0.8943 \cdot 0.275}=q^{H}(s)
\end{aligned}
$$

which can be substituted into (18) to yield:

$$
A(s)=\frac{r}{\alpha} q^{F}(s)^{1-\alpha}
$$


While $S_{w}=\left(1-\tau_{L}\right)\left[1+\frac{(1-n) \bar{b}}{n \ell}\right]$ is a given number, $S_{r}(s)=\left[\left(1-\tau_{K}\right) r-\frac{g+\delta_{k}}{s}\right]$ is a function of $s$ alone. Since human capital investment is expected to be more human capital-intensive than goods production (i.e., $\gamma<\alpha=0.28$ ), we set the benchmark value of $\gamma=0.25 .^{16}$ From (48) and (26), we have:

$$
\begin{aligned}
& D+\widetilde{D}\left(q^{H}(s)\right)^{\gamma}=\frac{g}{n(1-\ell)} \\
\rho+(1+\rho) g= & \left\{\gamma D+(1-\gamma)\left[D+\widetilde{D}\left(q^{H}\right)^{\gamma}\right]\right\}[n+(1-n) \bar{b}] \\
= & \left\{\gamma D+(1-\gamma) \frac{g}{n(1-\ell)}\right\}[n+(1-n) \bar{b}]
\end{aligned}
$$

From the latter expression, we solve $D(s)$, which can then be plugged into the former to derive $\widetilde{D}(s)$. These can then be substituted into (11) and (31) to obtain, respectively:

$$
\begin{gathered}
w(s)=\frac{\left(1-\tau_{K}\right) r}{\left(1-\tau_{L}\right) \gamma \widetilde{D}(s)}\left(q^{H}(s)\right)^{1-\gamma}\left[D(s)+\widetilde{D}(s)(1-\gamma)\left(q^{H}(s)\right)^{\gamma}\right] \\
\phi(s)=\frac{\eta}{(r+\psi) n}\left[(1-\alpha)-\frac{\alpha w(s)}{r q^{F}(s)}\right]
\end{gathered}
$$

By writing (21), (49) and (50), we now get, respectively:

$$
\begin{gathered}
\frac{T}{h}(s)=w\left[\tau_{L} n \ell-\left(1-\tau_{L}\right)(1-n) \bar{b}\right]+\tau_{K} r s \frac{k}{h} \\
\frac{\pi}{h}(s)=n \ell\left\{A\left(q^{F}(s)\right)^{\alpha}[(1-\alpha)-\phi v]-w(s)\right\} \\
\frac{c}{h}(s)=\left(S_{w} w(s)+S_{r}(s) q^{F}(s)\right) n \ell+\frac{\pi}{h}(s)+\frac{T}{h}(s)
\end{gathered}
$$

The above expressions can then be substituted into (30) to compute $s=0.9981$. Thus, in this calibrated economy, most of the physical capital inputs are used for goods production. By plugging the calibrated value of $s$ into the above functions of $s$, we can then compute: $q^{F}=1.539, q^{H}=0.007908, A=0.1648, D=0.01779$, $\widetilde{D}=0.001715, \phi=3.631, \frac{T}{h}=0.01033, \frac{\pi}{h}=0.01588$, and $\frac{c}{h}=0.05977$. Thus, the lump-sum government and firm profit redistributions and household consumption are about $8.6 \%, 12.3 \%$, and $50.0 \%$, respectively, in our benchmark economy. We can further plug in the value of $w$ into (29) to compute $\Delta=0.7161$.

We summarize the observables, benchmark parameter values and calibrated values of key endogenous variables in Table 1. To ensure the working of each channel discussed 
in the theory, we simulate the benchmark model to examine quantitatively the effects of two factor tax rates $\left(\tau_{K}\right.$ and $\left.\tau_{L}\right)$ on an array of endogenous variables of interest, including the balanced growth rate $(g)$, effective consumption $(c / h)$, the physicalhuman capital ratio $(k / h)$, effective output $(y / h)$, employment $(n)$, work effort $(\ell)$, the wage $(w)$, the wage discount $(\Delta)$, the workers' job finding rate $(\mu)$, the firms' employee recruitment rate $(\eta)$, and firms' vacancies $(v)$. The results obtained based on the responses of these endogenous variables around the balanced growth equilibrium to a $10 \%$ increase in each of the factor tax rates are reported in Table 2.

In our calibrated economy, we can now quantify the effects of the two factor tax rates $\left(\tau_{K}\right.$ and $\left.\tau_{L}\right)$ on the bargained wage and the wage discount in our calibrated economy. A higher capital tax is found to lower the bargained wage and to raise the wage discount slightly, whereas a higher labor tax raises the bargained (pre-tax) wage rate but lowers the wage discount. While both factor taxes discourage vacancy creation and suppress employment, the negative effects of capital taxation are much stronger than those of labor taxation. In response to either capital or labor taxation, the market becomes tighter to workers (i.e., $\theta=\frac{v}{u}$ is lower) and hence it is easier for firms to recruit but harder for workers to locate jobs. Either tax suppresses learning effort and the balanced growth rate, as well as the after-tax capital rental rate and the after-tax effective wage rate. Since factor taxation has a stronger negative effect on the taxed factor, the physical-human capital ratio falls in response to higher capital taxation, but rises in response to higher labor taxation. Our numerical results also suggest that a higher capital tax rate reduces output and consumption more than proportionately than human capital, whereas labor taxation suppresses human capital more than proportionately than output. Furthermore, since factor taxation encourages a shift from market to tax-exempt nonmarket activity, it partly offsets the distortion on households' incentives to accumulate human capital. This, together with a small calibrated value of the technology parameter $\widetilde{D}$, implies that the $H A$ locus is not too responsive to changes in the factor taxes. On the contrary, either tax increase reduces firm efficiency, thus implying a sizable downward shift in the $F E$ locus. Our numerical results suggest that capital taxation induces a larger shift in the $F E$ locus. As a result, capital taxation causes a larger drop in employment and balanced growth compared to labor taxation. 


\subsection{Factor Tax Incidence under Flat Taxes}

We are now prepared to conduct tax incidence analysis in our endogenously growing economy. In particular, we change the composition of the two factor tax rates by keeping the government revenue unchanged.

\subsubsection{Benchmark}

Under the pre-existing rates $\left(\tau_{K}, \tau_{L}\right)=(20 \%, 20 \%)$, the effective lump-sum tax is computed as $(T / h)^{*}=0.0103$. This benchmark value will be kept constant and the government budget constraint (21) will remain balanced in our revenue-neutral taxincidence exercises.

We next compute the social welfare measure along the BGP. Setting $h_{0}=k_{0}=1$, we can calculate the lifetime utility as follows: ${ }^{17}$

$$
\Omega\left(\tau_{K}, \tau_{L}\right)=\frac{1+\rho}{\rho}\left[\ln \left(\frac{c}{h}\left(\tau_{K}, \tau_{L}\right)\right)+m\left(1-n\left(\tau_{K}, \tau_{L}\right)\right)+\frac{1}{\rho} \ln \left(1+g\left(\tau_{K}, \tau_{L}\right)\right)\right]
$$

where effective consumption is given by (50) with $T / h=(T / h)^{*}$. In short, social welfare is mainly driven by three endogenous variables: effective consumption $\left(\frac{c}{h}\right)$, leisure $(1-n)$ and the economy-wide balanced growth rate $(g)$, all of which depend on factor tax rates $\left(\tau_{K}, \tau_{L}\right)$.

Figure 4 plots the tax incidence results. From Table 2, an increase in either the capital tax or the labor tax rate from its benchmark value of $20 \%$ leads to higher effective consumption as a result of a larger reduction in human capital. The effect of a shift from labor to capital taxation on effective consumption turns out to be humpshaped and peaked at around $\tau_{K}=20.57 \%$. In contrast, a shift from labor to capital taxation always reduces growth. Moreover, there is an effect via leisure. Combining

all together, we find that our welfare measure (the lifetime utility of a household) is hump-shaped and maximized at $\left(\tau_{K}^{*}, \tau_{L}^{*}\right)=(16.11 \%, 24.09 \%)$. That is, in the absence of other tax alternatives, the socially optimal factor tax mix requires a decrease in the capital tax rate in conjunction with an increase in the labor tax rate from their benchmark values. Such a tax reform will lead to a $0.203 \%$ increase in economic growth and a $0.016 \%$ increase in welfare, which is a $0.039 \%$ increase in consumption equivalence. Moreover, one may ask how much the welfare loss is if one would set the capital tax rate at zero. Our quantitative analysis suggests such a loss is in the order 
of $0.649 \%$ in consumption equivalence. Our finding that the optimal capital tax rate is significantly larger than zero is in contrast to the conventional tax incidence literature within both the exogenous and endogenous growth frameworks.

Quantitative Result 1. For the tax incidence exercises in response to a shift from labor to capital taxation, effective consumption and welfare are both hump-shaped whereas economic growth and leisure are both decreasing. Under the benchmark parametrization, the optimal tax mix features a moderate shift from capital to labor taxation but the optimal capital tax rate is far above zero.

It is important to understand the numerically dominant channel underlying this finding: the vacancy creation-market participation channel with endogenous human capital in a non-Walrasian economy with labor market frictions. Specifically, if initially the capital tax rate is too low, then a higher tax on capital income accompanied by a revenue-neutral reduction in the labor tax turns out to raise the (endogenous) wage discount and to encourage firms to create more vacancies. This in turn raises the (endogenous) job finding rate and hence induces workers to more actively participate in the labor market to seek employment. Because this leads to positive effects on employment and output growth under endogenous human capital accumulation, a shift from a zero to a positive capital tax rate becomes welfare-improving, thereby yielding a policy recommendation different from that of Chamley-Judd-Lucas.

It is noted that under the Chamley (1986) framework with a representative household, Straub and Werning (2014) showed that when capital taxation is not subject to an upper bound, the optimal capital tax rate is zero and that a positive optimal capital tax can be obtained when there is a bound. In contrast, we establish a positive optimal capital tax rate without any of such bound. Admittedly, a full analysis of the quantitative effect would require incorporation of the Straub-Werning arguments to our model, which is by no means straightforward but certainly beyond the scope of the present paper.

\subsubsection{Sensitivity Analysis}

While our pre-set parameters in the calibration exercises are all justified basically, some of the calibration criteria may be open to discussion. We therefore perform sensitivity analysis to check the robustness of our results. In particular, we consider the following 
alternatives:

(i) We allow the worker elasticity of matching, $\beta$, to take alternative values used in the literature, including 0.235 (Hall 2005), 0.54 (Hall and Milgrom 2008) and 0.72 (Shimer 2005).

(ii) We allow the leisure parameter, $m$ (which is a combination of the preference parameter $\tilde{m}$ and the intensity of enjoyment $G(z)$ ), to be $50 \%$ below and above its benchmark value.

(iii) We allow the labor-market tightness, $\theta=v /(1-n)$, the ratio of the unemployment compensation to the market wage, $\bar{b}$, and the capital share of human capital accumulation, $\gamma$, to be $10 \%$ below and above their respective benchmark values.

(iv) We allow the amount of physical capital to be half or twice as large as the amount of human capital, i.e., $k / h=0.5,2$.

(v) We allow the pre-existing tax rates to take alternative values used in previous studies, $\left(\tau_{K}, \tau_{L}\right)=(35 \%, 20 \%)\left(\right.$ Judd 1987) and $\left(\tau_{K}, \tau_{L}\right)=(40 \%, 36 \%)$ (Lucas 1990).

The sensitivity analysis results are reported in Table $3{ }^{18}$

When we recalibrate the model with different capital shares of human capital accumulation, or different physical-human capital ratios, labor-market matching, bargaining and human capital accumulation are either unchanged or changed only negligibly. Thus, the wage discount effect and the vacancy creation-market participation channel are essentially identical to those in the benchmark case, thereby leaving the factor tax incidence result largely unaffected.

When we vary the worker elasticity of matching to take alternative values $\beta=$ $\{0.235,0.54,0.72\}$ used by Hall (2005), Hall and Milgrom (2008) and Shimer (2005), respectively, the optimal capital tax rate ranges from $10 \%$ to $23 \%$, all significantly higher than zero. The higher the worker elasticity of matching is, the more important workers contribute to labor-market matching. As a consequence, labor taxation becomes more distortive and, eventually, when worker elasticity of matching is above a threshold level ( $\beta$ about 0.56 ), the optimal tax mix features a shift from labor to capital taxation. 
Quantitative Result 2. Within a reasonable parameter range, the optimal tax mix always features a shift from capital to labor taxation compared to the pre-existing tax rates and the optimal capital tax rate is always positive, regardless of the relative magnitude of the bargaining share to the household $(\zeta)$ to the labor share in matching production $(\beta)$.

When the leisure parameter $m$ is $50 \%$ above its benchmark value, the optimal tax mix still features a shift from capital to labor taxation: $\left(\tau_{K}^{*}, \tau_{L}^{*}\right)=(21.10 \%, 18.77 \%)$, but such a shift is much smaller than the benchmark case. When the leisure parameter is $50 \%$ below its benchmark value, the optimal tax mix becomes: $\left(\tau_{K}^{*}, \tau_{L}^{*}\right)=$ $(9.34 \%, 30.47 \%)$, featuring a larger shift from capital to labor taxation but still with a significantly positive tax on capital income. Notably, when $m$ is sufficiently large in magnitude, for example twice as large as its benchmark value $(m=-0.064 \cdot 2=$ $-0.128)$, the direct effect of labor taxation on leisure is so strong that the detrimental effect of a higher labor tax on the marginal benefit of the household in a wage bargain is larger than that of a higher capital tax. Due to its greater distortion on the wage discount, labor taxation becomes more harmful to welfare and the optimal tax mix in this case turns out to feature a shift from labor to capital taxation: $\left(\tau_{K}^{*}, \tau_{L}^{*}\right)=(25.01 \%, 14.03 \%) \cdot{ }^{19}$

When the labor-market tightness measure $\theta$ is $10 \%$ higher than its benchmark value, the labor market is less tight to workers. As workers become less vulnerable to labor taxation, it is better to tax them. The optimal tax mix therefore features a larger shift from capital to labor taxation: $\left(\tau_{K}^{*}, \tau_{L}^{*}\right)=(2.25 \%, 35.00 \%)$. On the contrary, when $\theta$ is $10 \%$ lower, workers become more vulnerable to labor taxation and the optimal tax mix turns out to feature a shift from labor to capital taxation: $\left(\tau_{K}^{*}, \tau_{L}^{*}\right)=(32.78 \%, 1.23 \%)$. As one can see, when the labor-market tightness measure is further away from its benchmark value, the optimal tax mix will feature complete elimination of either capital taxation (with much less tightness to workers) or labor taxation (with much greater tightness to workers).

Our quantitative results are not too sensitive to either the unemployment compensationmarket wage ratio $\bar{b}$ or the capital share of human capital accumulation $\gamma$. When $\bar{b}$ is $10 \%$ higher, it is required that the government raises both tax rates in order to maintain a balanced budget. Relatively speaking, however, the overall distortion of $\tau_{L}$ 
reduces because of better insurance provision against the unemployment state. Therefore, the optimal tax mix becomes: $\left(\tau_{K}^{*}, \tau_{L}^{*}\right)=(16.03 \%, 24.12 \%)$, which features a marginally larger shift from capital to labor taxation. When $\gamma$ is $10 \%$ higher, more capital is required for human capital accumulation. Since education/learning is fully tax-exempt, the overall distortion of $\tau_{K}$ is lower. In this case, the optimal tax mix is: $\left(\tau_{K}^{*}, \tau_{L}^{*}\right)=(16.44 \%, 23.75 \%)$, featuring a marginally smaller shift from capital to labor taxation.

Finally, when pre-existing tax rates take the values used by Judd $(1987)$ at $\left(\tau_{K}, \tau_{L}\right)=$ $(35 \%, 20 \%)$ with a much higher capital tax rate initially, the optimal tax mix turns out to be very close to the pre-existing mix: $\left(\tau_{K}^{*}, \tau_{L}^{*}\right)=(34.97 \%, 20.04 \%)$, featuring a quantitatively negligible shift from capital to labor taxation. When both of the preexisting tax rates take higher values $\left(\tau_{K}, \tau_{L}\right)=(40 \%, 36 \%)$ as used by Lucas (1990), the optimal factor tax mix becomes: $\left(\tau_{K}^{*}, \tau_{L}^{*}\right)=(42.75 \%, 32.08 \%)$, now featuring a small shift from labor to capital taxation. In both cases, it is still optimal to tax capital as in the benchmark economy and in the latter case replacing labor by capital taxation actually enhances welfare. Because the pre-existing factor tax distortions are almost optimal, the welfare gains from the respective tax reforms are very small.

\subsection{Dynamic Tax Incidence}

We turn next to calibrating the two factor tax schedules proposed in Section 5 above. The initial tax rates are given at the pre-existing levels $\left(\tau_{K_{0}}, \tau_{L_{0}}\right)=(20 \%, 20 \%)$, which satisfy the IR locus with the replacement ratio $\bar{b}$ fixed at 0.42 . The long-run asymptotic factor tax rates are given by their optimal values in the benchmark case: $\left(\tau_{K}^{*}, \tau_{L}^{*}\right)=(16.11 \%, 24.09 \%)$. To ensure the robustness of our benchmark results under flat taxes, we consider various transitional tax schemes:

(i) (Case 1) $\tau_{K_{t}}$ converges monotonically from $20 \%$ to $16.11 \%$ : $\tau_{K_{t}}=0.1611+0.0389$. $e^{-0.0637 \cdot t}, \tau_{L_{t}}=0.2409-0.0409 \cdot e^{-0.05931256 \cdot t}$;

(ii) (Case 2) $\tau_{K_{t}}$ drops instantaneously from $20 \%$ to $10 \%$ and $\tau_{L_{1}}$ jumps instantaneously from $20 \%$ to $28.69 \%$ and then converge monotonically to their optimal values in the benchmark case: $\tau_{K_{t}}=0.1611-0.0611 * e^{-0.0728 \cdot t}, \tau_{L_{t}}=$ $0.2409+0.04598475 * e^{-0.0821716 \cdot t}$; 
(iii) (Case 3) $\tau_{K_{t}}$ drops instantaneously from $20 \%$ to $5 \%$ and $\tau_{L_{1}}$ jumps instantaneously from $20 \%$ to $32.08 \%$ and then converge monotonically to their optimal values in the benchmark case: $\tau_{K_{t}}=0.1611-0.1111 * e^{-0.0847 \cdot t}, \tau_{L_{t}}=$ $0.2409+0.07993234 * e^{-0.097084646 \cdot t} ;$

(iv) (Case 4) $\tau_{K_{t}}$ drops instantaneously from $20 \%$ to 0 and $\tau_{L_{1}}$ jumps instantaneously from $20 \%$ to $35.02 \%$ and then converge monotonically to their optimal values in the benchmark case: $\tau_{K_{t}}=0.1611-0.1611 * e^{-0.0922 \cdot t}, \tau_{L_{t}}=0.2409+0.10934954 *$ $e^{-0.1067882 \cdot t}$.

(v) (Case 5) $\tau_{K_{t}}$ drops instantaneously from $20 \%$ to $-10 \%$ (i.e., capital subsidy) and $\tau_{L_{1}}$ jumps instantaneously from $20 \%$ to $39.89 \%$ and then converge monotonically to their optimal values in the benchmark case: $\tau_{K_{t}}=0.1611-0.2611 * e^{-0.1018 \cdot t}$, $\tau_{L_{t}}=0.2409+0.15795212 * e^{-0.11960536 \cdot t}$.

In all cases, $\left(\tau_{L_{t}}, \tau_{K_{t}}\right)$ satisfy the IR locus. Moreover, we determine the converging speed such that the gap between the initial and the asymptotic levels of both tax rates to be $1 \%$ of their respective long-run values in the 50 th period.

To compare welfare along the transitional path with that in the BGP equilibrium, we denote $\frac{\widetilde{c}}{h}$ as the BGP level of effective consumption and $\frac{c}{h}\left(\tau_{K t}, \tau_{L t}\right)$ as the corresponding values along the transitional path. We approximate lifetime utility up to the 50th period and use the following equation to derive the consumption equivalence $(C E)$ measure:

$$
\sum_{t=0}^{50}\left(\frac{1}{1+\rho}\right)^{t}\left[\ln \left[\frac{(1+C E) \frac{\widetilde{c}}{h}}{\frac{c}{h}\left(\tau_{K t}, \tau_{L t}\right)}\right]\right]=0
$$

We compute the consumption equivalence in the five cases, which are:

(i) (Case 1) $C E=0.4385 \%$;

(ii) (Case 2) $C E=0.4905 \%$;

(iii) (Case 3) $C E=0.6385 \%$;

(iv) (Case 4) $C E=0.7576 \%$;

(v) (Case 5) $C E=0.9347 \%$. 
Thus, the highest welfare is reached when the capital tax rate is negative in period 1 (capital subsidy), gradually rising to the long-run optimal tax level.

Intuitively, the unemployment compensation is essential for the extensive margin of labor force decision, which is fixed in the transition. While the labor income tax is crucial for both intratemporal work-learning effort trade-off and intertemporal human capital accumulation, the capital income tax affects critically both intratemporal physical capital allocation and intertemporal physical capital accumulation. Our quantitative analysis suggests that, along the transition, the effect of $\tau_{K t}$ on effective consumption is negative, whereas that of $\tau_{L t}$ is basically negligible. As a result, the detrimental effect of the capital tax outweighs that of the labor tax. Therefore, the tax incidence of changing the mix of capital and labor taxes is in favor of taxing more heavily on labor income while subsidizing capital to minimize the harmful impact of capital taxation. This dynamic tax incidence result is in contrary to that in Chamley (1986), wherein in early periods the government raises revenues on existing capital as much as possible, while the government generates revenues only by taxing wage income in the long run. Nonetheless, even in this best case scenario, the welfare gain compared to flat tax is modest, only $0.7576 \%$ in consumption equivalence.

\section{Extensions}

To better understand the key factors driving the main results, we now check various setups, labeled as Models I-VI, that may potentially change the relative distortion of capital and labor taxes. The first is devoted to studying the role played by endogenous leisure, whereas the second to understanding whether zero capital taxation at optimum may still hold under the linear human capital setup proposed by Lucas (1990). In the next two exercises, we try to differentiate the role between endogenous human capital and endogenous growth. We then examine the importance of labor market frictions by investigating the case of a frictionless Walrasian economy, followed by the consideration of a third instrument beyond factor taxation - the replacement ratio. Table 4 summarizes the main tax incidence results. 


\subsection{Model I: Inelastic Leisure}

In the benchmark model with endogenous labor-leisure choice, labor-related decisions become more elastic, implying that the tax on labor income is more distortionary than the case with inelastic leisure. While this labor participation response is tied to the labor-leisure trade-off, just how important such a channel is to the optimal tax mix outcome is a quantitative matter.

To check the robustness of our quantitative findings, we consider the case of inelastic leisure with $m=0$. By performing tax incidence analysis, we find that the optimal tax $\operatorname{mix}\left(\tau_{K}^{*}, \tau_{L}^{*}\right)$ is now at $(9.05 \%, 31.33 \%)$, featuring a sizable shift from capital to labor taxation (though the optimal capital tax rate is still far above zero). This suggests that, by removing the labor-leisure trade-off, taxing labor becomes quantitatively much less harmful. In this case, a tax reform will lead to a nonnegligible welfare gain of $0.20 \%$ (in consumption equivalence).

Quantitative Result 3. The optimal capital tax is positive even by removing the labor-leisure trade-off. By removing such a trade-off, however, it is optimal to shift more tax burden to labor income.

\subsection{Model II: Linear Human Capital Accumulation Function}

In the benchmark case, we assume that human capital and physical capital are both required for human capital accumulation. Now we consider an alternative setup of human capital formation where only human capital is used as an input (the Lucasian human capital formation). One can think of this as a special case of (2) with $\widetilde{D}=0$ and $s=1$, that is,

$$
h_{t+1}-h_{t}=D n_{t}\left(1-\ell_{t}\right) h_{t}
$$

The modified optimization and BGP conditions are presented in the Appendix. In this case, the calibrated value of $D$ is fairly close to the benchmark setup $(D=$ 0.0182), whereas the calibrated bargaining share to household parameter is moderately higher $(\zeta=0.3254)$. Recall that human capital production is fully tax-exempt. When market goods (physical capital) are no longer inputs to human capital accumulation, the entirety of physical capital must be subject to taxation. As a consequence, the overall distortion of $\tau_{K}$ rises and the optimal tax mix now features a larger shift from 
capital to labor taxation: $\left(\tau_{K}^{*}, \tau_{L}^{*}\right)=(4.99 \%, 46.68 \%)$, which generates a larger welfare gain of $1.5407 \%$ (in consumption equivalence), compared to the benchmark case. Thus, elimination of the interactions between physical and human capital in the process of human capital accumulation tends to lower the distortion of labor taxation relative to capital taxation. Nonetheless, the optimal tax mix still features a positive capital tax rate even under this simple Lucasian form of human capital accumulation.

Quantitative Result 4. Under a simple Lucasian form of human capital accumulation, the optimal capital tax is still positive but at a lower rate than in the benchmark economy.

\subsection{Model III: Exogenous Human Capital}

We next differentiate the role between endogenous human capital and endogenous growth. To begin, we consider the case of exgenous human capital, which can be viewed as one capturing the case discussed in Domeij (2005) where the Hosios' rule is met. This is equivalent to setting $\ell=1, s=1, h=1$ and $g=0$, while eliminating the human capital accumulation equation (2), the nonmarket effective capital-labor ratio $q^{H}$ and the associated condition (11). By performing tax incidence analysis, the optimal tax mix $\left(\tau_{K}^{*}, \tau_{L}^{*}\right)$ is now at $(0 \%, 42.55 \%)$. That is, at optimum, capital taxation is fully replaced by labor taxation, indicating that endogenous human capital is essential for obtaining a positive optimal capital tax rate.

Quantitative Result 5. In a model with exogenous human capital, it is optimal to fully eliminate capital taxation by taxing only labor income.

The essential role of endogenous human is readily understood. Without it, search and matching frictions under Hosios' rule is not enough to make labor taxation more distortionary than capital taxation, as argued by Domeij (2005). With endogenous human capital, we incorporate three additional quantitatively important channels of labor tax distortion: one via the growth effect of human capital accumulation, the second via capital-labor reallocation in the education sector, and the third via the endogenous wage discount influenced by the interactions between the vacancy creationmarket participation channel and the human capital channel. These quantitatively over-turn the finding of full elimination of capital taxation. 


\subsection{Model IV: Exogenous Growth with Endogenous Human Capital}

We have learned from Quantitative Result 5 that endogenous human capital is crucial for the positive optimal capital taxation finding. One may now inquire whether endogenous growth is essential. This can be checked by fixing the growth rate at a given benchmark value, $g=0.0045$, when we conduct tax incidence exercises. In this case, we still allow human capital to be endogenously accumulated. We find that the optimal tax mix $\left(\tau_{K}^{*}, \tau_{L}^{*}\right)$ is at $(16.19 \%, 24.01 \%)$, featuring a shift from capital to labor taxation with the optimal capital tax rate slightly above its benchmark counterpart (16.11\%). This result can be understood by examining Figure 4 where capital taxation is more harmful for economic growth than labor taxation; thus, by setting the growth rate at an exogenous level, one may tax capital more (though only marginally higher). In this case, a tax reform has a slightly smaller welfare gain of $0.03889 \%$ (in consumption equivalence), compared to the benchmark case. Nonetheless, our finding indicates that endogenous growth alone is inconsequential for the optimal capital tax rate to be positive.

Quantitative Result 6. In an exogenous growth model with endogenous human capital accumulation, the optimal capital tax is positive and at a higher rate than in the benchmark economy.

\subsection{Model V: Walrasian Economy}

To highlight the role played by labor-market frictions, we investigate the tax incidence outcome in a frictionless Walrasian economy with full employment. By construction, $n=1$ and hence there is no labor-leisure trade-off (i.e., $m(1-n)=0$ ). The modified optimization and BGP conditions are presented in the Appendix. By comparing it with the optimal tax mix result in our benchmark case, the role of labor-market frictions can be identified. Specifically, we find that the optimal tax mix becomes: $\left(\tau_{K}^{*}, \tau_{L}^{*}\right)=$ $(0 \%, 27.51 \%)$, which restores the Lucasian policy recommendation - the optimal tax mix in the Lucas $(1990)$ case is $\left(\tau_{K}^{*}, \tau_{L}^{*}\right)=(0 \%, 46 \%)$ based on higher pre-existing tax rates $\left(\tau_{K}, \tau_{L}\right)=(40 \%, 36 \%)$. Thus, even in a human capital-based endogenous growth model, one should replace capital taxation fully by labor taxation if the labor market is frictionless. This suggests that labor-market frictions are essential for obtaining a different tax incidence conclusion from previous studies. 
Quantitative Result 7. In a model with a Walrasian frictionless labor market, it is optimal to fully eliminate capital taxation by taxing only labor income.

\subsection{Model VI: An Alternative Instrument}

Thus far, our model only allows for two tax instruments, namely, capital and labor income taxes. We turn now to adding a third instrument, namely the replacement ratio while maintaining effective lump-sum transfer to households as in the bench-

mark to ensure government revenue-neutral. We find an optimal replacement ratio at $\bar{b}^{*}=0.577$, which is 15.7 percentage points higher than its benchmark value. The corresponding optimal capital and labor tax rates are $\left(\tau_{K}^{*}, \tau_{L}^{*}\right)=(15.96 \%, 24.05 \%)$. Thus, compared to the benchmark, a higher replacement ratio at optimum does require a bit more labor but less capital tax to finance. Even with the optimal replacement ratio as a third instrument, our main conclusion is that the socially optimal factor tax mix requires a shift from the capital to the labor tax, though it is never optimal to completely eliminate the capital tax.

\section{7 $\quad$ Summary}

The above exercises promote better understanding of the key drivers of the factor tax incidence results. While endogenous human capital and labor market frictions are essential for the conclusion of a positive optimal capital tax, endogenous leisure, nonlinear human capital accumulation and endogenous growth are not crucial.

\section{Concluding Remarks}

In this paper, we have developed a human capital-based endogenous growth framework with labor market search and matching frictions that permit individuals to participate in the labor force voluntarily. By conducting tax incidence exercises quantitatively, we have found that it is never optimal to set the capital tax rate to zero when both physical and human capital are used as inputs of human capital accumulation. We have also found that, in the benchmark case with physical capital entering the human capital accumulation process and with a pre-existing flat rate of $20 \%$ on both capital and labor income, a partial shift from capital to labor taxation maximizes social welfare 
- this main finding is robust to different parameterization as well as to alternative setups with inelastic leisure, or with a Lucasian human capital accumulation process that is independent of market goods (physical capital), or with exogenous growth. The main drivers leading to a positive optimal capital tax are endogenous human capital in conjunction with frictional labor markets. Our results suggest that, in order to enhance social welfare, a proper tax reform must take into account labor market frictions. When such frictions are substantial, fully replacing capital with labor income taxation can be welfare-retarding. This main conclusion is robust even along the transition and by considering optimal replacement ratio of unemployment compensation.

For future research along these lines, it is perhaps most interesting to incorporate a pecuniary vacancy creation cost that requires capital financing. In the presence of credit market frictions as a result of private information, such a financing constraint is anticipated to increase the capital tax distortion. On the contrary, one may also extend the model to allow the separation rate to depend on on-the-job learning effort (as in Mortensen 1988). Since the labor income tax discourages on-the-job learning, it is anticipated that such a generalization may cause the labor tax to be more distorted. Thus, both extensions call for a revisit of tax incidence exercises: while the former may favor a shift from taxing capital to taxing labor income, the latter may yield opposite policy outcomes. 


\section{NOTES}

1. Equivalently, the externality can be thought of as arising from one additional firm with a vacancy which increases the probability that a job-seeker will match with a firm but decreases the probability that firms with vacancies already posted will match with a job-seeker.

2. There is a recent strand in the literature on optimal taxation which does not incorporate human capital, but instead considers nonlinear labor taxation, alternative non-factor taxes, incentive problems and/or political economy. Its focus is very different from ours.

3. See Jacobson, LaLonde and Sullivan (1993) and Laing, Palivos and Wang (2003) for a further discussion of the human capital depreciation of displaced workers. We could follow Chen, Chen and Wang (2011) to consider a general setting of human capital formation with the unemployed workers allowed to accumulate human capital. While the analysis becomes much more complicated, our main findings remain valid.

4. In line with the literature, we rule out double taxation assuming profit redistribution is tax-exempt. Moreover, in the interest of factor tax incidence, we shall not add other types of taxes such as consumption taxes, as such an addition would not cause major change in the relative advantage of the factor taxes.

5. Although the setup of $G(z)$ is not important in our theoretical analysis, it is crucial for calibrating the value of leisure.

6. We note that the second-order conditions and the concavity property of the value functions for the household's and firm's optimization are rather complex, which are relegated to the Appendix.

7. Again, we relegate the second-order condition of the wage bargaining problem to the Appendix.

8. In balanced growth equilibrium to be defined below with constant factor tax rates, allowing for debt financing would not make any difference, as this does not create a motive for a saving distortion.

9. Suppose the utility function takes a constant elasticity of intertemporal substitution form. It can be easily verified that, should this elasticity be different from one, (10) would violate the BGP requirements.

10. We suspect that a key assumption leading to a positive optimal capital tax is that workers are hand to mouth without saving. This is because, in such a case, the detrimental effect of capital taxation is dampened.

11. Since the wage herein is determined by cooperative bargaining, it is not easy to derive a clean condition as in the Walrasian framework of Bond, Wang and Yip (1996).

12. While the "simple tax structure" approach via elasticities of changes in income tax rates in models with heterogeneous agents (e.g., Saez, 2001) provides a simple link between optimal tax formulas and elasticities of earnings familiar to empirical studies, our model uses the approach that follows from Judd (1985), Chamley (1986) and Lucas 
(1990). Our approach is standard in the study of the optimal Ramsey tax in models with homogeneous agents.

13. All the conditions imposed (Conditions G, LC and FP) will be verified in our calibrated benchmark economy.

14. In our quantitative analysis, we have targeted our model to the U.S. economy; we thus choose the initital tax rates at $(20 \%, 20 \%)$ which subsequently provides an effective government revenue based on which our revene-neutral tax incidence exercises are conducted. It should be noted that without pre-existing factor tax distoration, it remains best not to tax factor incomes, consistent with our theoretical results presented in Proposition 5.

15. For detailed data documentation on labor and time allocation, the reader is referred to Chen, Chen and Wang (2011).

16. For $\gamma$ and other preset parameters, sensitivity analysis will be conducted to check the robustness of our findings.

17. See the proof in Chen, Chen and Wang (2011) in a similar context of welfare computation.

18. In some cases, we do not report the welfare loss from setting $\tau_{K}=0$, because there is no $\tau_{L}<1$ to maintain revenue neutral.

19. We shall relegate the discussion of the inelastic leisure case $(m=0)$ to the next section. 


\section{References}

[1] Andolfatto, David (1996), "Business Cycles and Labor-Market Search," American Economic Review, 86: 112-132.

[2] Blanchard, Oliver and Peter Diamond (1990), "The Cyclical Behavior of the Gross Flows of U.S. Workers," Brookings Papers on Economic Activity, 2: 85-143.

[3] Bond, Eric, Ping Wang and Chong K. Yip (1996), "A General Two-Sector Model of Endogenous Growth with Human and Physical Capital: Balanced Growth and Transitional Dynamics," Journal of Economic Theory, 68: 149-173.

[4] Chamley, Christophe (1985a), "Efficient Tax Reform in a Dynamic Model of General Equilibrium," Quarterly Journal of Economics, 100: 335-356.

[5] Chamley, Christophe (1985b), "Efficient Taxation in a Stylized Model of Intertemporal General Equilibrium," International Economic Review, 26: 451-468.

[6] Chamley, Christophe (1986), "Optimal Taxation of Capital Income in General Equilibrium with Infinite Lives," Econometrica, 54: 607-622.

[7] Chen, Been-Lon (2007), "Factor Taxation and Labor Supply in a Dynamic OneSector Growth Model," Journal of Economic Dynamics and Control, 31: 39413964 .

[8] Chen, Been-Lon, Hung-Ju Chen and Ping Wang (2011), "Labor-Market Frictions, Human Capital Accumulation, and Long-Run Growth: Positive Analysis and Policy Evaluation," International Economic Review, 52: 131-160.

[9] Chen, Been-Lon and Chia-Hui Lu (2013), "Optimal Factor Tax Incidence in Twosector Human Capital-based Models," Journal of Public Economics, 97: 75-94.

[10] Diamond, Peter A. (1982a) "Aggregate Demand Management in Search Equilibrium," Journal of Political Economy, 90: 881-894.

[11] Diamond, Peter A. (1982b), "Wage Determination and Efficiency in Search Equilibrium," Review of Economic Studies, 49: 217-227.

[12] Domeij, David (2005), "Optimal capital taxation and labor market search," Review of Economic Dynamics, 8: 623-650.

[13] Guo, Jang-Ting and Kevin J. Lansing (1999), "Optimal Taxation of Capital Income with Imperfectly Competitive Product Markets," Journal of Economic Dynamics and Control, 23: 967-995.

[14] Hall, Robert E. (2005), "Employment Fluctuations with Equilibrium Wage Stickiness," American Economic Review, 95: 50-65. 
[15] Hall, Robert E. and Paul R. Milgrom (2008), "The Limited Influence of Unemployment on the Wage Bargain," American Economic Review, 98: 1653-1674.

[16] Hosios, Arthur J. (1990), "On the Efficiency of Matching and Related Models of Search and Unemployment," Review of Economic Studies, 57: 279-298.

[17] Jacobson, Louis S., Robert J. LaLonde and Daniel Sullivan (1993), "Earnings Losses of Displaced Workers," American Economic Review, 83: 685-709.

[18] Jones, Larry E., Rodolfo E. Manuelli and Peter E. Rossi (1993), "Optimal Taxation in Models of Endogenous Growth," Journal of Political Economy, 101: 485517.

[19] Jones, Larry E., Rodolfo E. Manuelli and Peter E. Rossi (1997), "On the Optimal Taxation of Capital Income," Journal of Economic Theory, 73: 93-117.

[20] Judd, Kenneth L. (1985), "Redistributive Taxation in a Simple Perfect Foresight Model," Journal of Public Economics, 28: 5983.

[21] Judd, Kenneth L. (1987), "The Welfare Cost of Factor Taxation in a Perfect Foresight Model," Journal of Political Economy, 95: 675-709.

[22] Kendrick, John W. (1976), The Formation and Stocks of Total Capital, New York: Columbia University Press.

[23] Lansing, Kevin (1999) "Optimal redistributive capital taxation in a neoclassical growth model," Journal of Public Economics 73, 423-453.

[24] King, Robert and Sergio Rebelo (1990), "Public Policy and Economic Growth: Developing Neoclassical Implications," Journal of Political Economy, 98: S126S150.

[25] Laing, Derek, Theodore Palivos and Ping Wang (1995), "Learning, Matching, and Growth," Review of Economic Studies, 62: 115-129.

[26] Laing, Derek, Theodore Palivos and Ping Wang (2003), "The Economics of New Blood," Journal of Economic Theory, 112: 106-156.

[27] Lu, Chia-Hui and Been-Lon Chen (2015), "Optimal Capital Taxation in a Neoclassical Growth Model," Journal of Public Economic Theory, 17: 257-269.

[28] Lucas, Robert E. Jr. (1988), "On the Mechanics of Economic Development," Journal of Monetary Economics, 22: 3-42.

[29] Lucas, Robert E. Jr. (1990), "Supply-side Economics: An Analytical Review," Oxford Economic Papers, 42: 293-316. 
[30] Merz, Monika (1995), "Search in the Labor Market and the Real Business Cycle," Journal of Monetary Economics, 36: 269-300.

[31] Mino, Kazuo (1996), "Analysis of a Two-Sector Model of Endogenous Growth with Capital Income Taxation," International Economic Review, 37: 227-251.

[32] Mortensen, Dale T. (1982), "Property Rights and Efficiency in Mating, Racing and Related Games," American Economic Review, 72: 968-969.

[33] Pissarides, Christopher A. (1984), "Efficient Job Rejection," Economic Journal, 94: S97-S108.

[34] Reis, Catarina (2011), "Entrepreneurial Labor and Capital Taxation," Macroeconomic Dynamics, 15: 326-335.

[35] Saez, Emmanuel (2001), "Using Elasticities to Derive Optimal Income Tax Rates," Review of Economic Studies, 68: 205-229.

[36] Shimer, Robert (2005), "The Cyclical Behavior of Equilibrium Unemployment and Vacancies," American Economic Review, 95: 25-49.

[37] Stokey, Nancy L. and Sergio Rebelo (1995), "Growth Effects of Flat-Rate Taxes," Journal of Political Economy, 103: 519-550.

[38] Straub, Ludwig and Ivan Werning (2014), "Positive Long Run Capital Taxation: Chamley-Judd Revisited", NBER Working Paper 20441. 


\section{Appendix}

(Not Intended for Publication)

In the Appendix, we provide mathematical details of the second-order conditions of household/firm optimization and wage bargaining, the concavity of household/firm value functions, quasi-socail planner's optimization, the centralized solution by coordinating labor matching and wage bargain, dynamic taxation, as well as the Alternative Models II (linear human capital accumulation) and III (Walrasian).

\subsection{Second-Order Conditions}

The second-order conditions of firm's optimization with respect to $v$ and $k$ are (to ease notation burden, we carry time subscript $t$ only for perpetually growing variables):

$$
\begin{gathered}
\frac{\partial^{2} \Gamma\left(n_{t}\right)}{\partial\left(v_{t}\right)^{2}}=\frac{\eta_{t}^{2}}{1+\bar{r}} \Gamma_{n n}\left(n_{t+1}\right)<0 \\
\frac{\partial^{2} \Gamma\left(n_{t}\right)}{\partial\left(k_{t}\right)^{2}}=\frac{s_{t}}{x_{t}} \alpha(\alpha-1) A\left(\frac{s_{t}}{n_{t} x_{t}}\right)^{\alpha-1}\left(k_{t}\right)^{\alpha-2}<0
\end{gathered}
$$

which hold automatically under our functional form specifications.

The second-order conditions of household's optimization with respect to $c_{t}, \ell_{t}$ and $s_{t}$ are:

$$
\begin{gathered}
\Omega_{c c}(\mathcal{H})=U_{c c}+\frac{1}{1+\rho} \Omega_{k k}\left(\mathcal{H}^{\prime}\right)<0 \\
\Omega_{\ell \ell}(\mathcal{H})=\frac{n_{t} h_{t}}{1+\rho}\left\{\left(1-\tau_{L_{t}}\right) w_{t}\left\{\Omega_{k k}\left(\mathcal{H}^{\prime}\right)\left(1-\tau_{L_{t}}\right) w_{t} n_{t} h_{t^{-}}\left[\Omega_{k h}\left(\mathcal{H}^{\prime}\right)+\Omega_{h k}\left(\mathcal{H}^{\prime}\right)\right]\left[D+\widetilde{D}(1-\gamma)\left(q_{t}^{H}\right)^{\gamma}\right] n_{t} h_{t}\right\}\right. \\
\left.-\Omega_{h}\left(\mathcal{H}^{\prime}\right) \widetilde{D} \gamma(1-\gamma)\left(q_{t}^{H}\right)^{\gamma-1} q_{t+1}^{H}\left(\ell_{t}\right)+\Omega_{h h}\left(\mathcal{H}^{\prime}\right)\left[D+\widetilde{D}(1-\gamma)\left(q_{t}^{H}\right)^{\gamma}\right]^{2} n_{t} h_{t}\right\}<0 \\
\Omega_{s s}(\mathcal{H})=\frac{k_{t}}{1+\rho}\left\{\left(1-\tau_{K_{t}}\right) r_{t} k_{t}\left[\Omega_{k k}\left(\mathcal{H}^{\prime}\right)\left(1-\tau_{K_{t}}\right) r_{t^{-}}\left[\Omega_{k h}\left(\mathcal{H}^{\prime}\right)+\Omega_{h k}\left(\mathcal{H}^{\prime}\right)\right] \widetilde{D} \gamma\left(q_{t}^{H}\right)^{\gamma-1}\right]\right. \\
\left.-\Omega_{h}\left(\mathcal{H}^{\prime}\right) \widetilde{D} \gamma(\gamma-1)\left(q_{t}^{H}\right)^{\gamma-2} q_{t}^{H}\left(s_{t}\right)+\Omega_{h h}\left(\mathcal{H}^{\prime}\right) k_{t}\left[\widetilde{D} \gamma\left(q_{t}^{H}\right)^{\gamma-1}\right]^{2}\right\}<0
\end{gathered}
$$

which also hold under our functional form specifications and parameterization in the benchmark model.

Finally, we turn to the second-order condition of wage bargaining. From (30), it is easily see that $M B_{w w}<0$ and $M C_{w w}>0$, thus assuring the second-order condition: $d\left(M B_{w}-M C_{w}\right) / d w<0$. 


\subsection{Wage Bargaining}

The bargained wage rate and the equilibrium wage can be derived by solving the following quadratic equation:

$$
S_{w}(1-\zeta) F_{1} w_{t}^{2}+\left\{S_{r} q_{t}\left[(1-\zeta) F_{1}+\zeta\right]-S_{w} F_{2}(1-\zeta)\right\} w_{t}-S_{r} q_{t}\left[(1-\zeta) F_{2}+\zeta(1-\alpha) A q_{t}^{\alpha}\right]=0
$$

where $F_{1}=\frac{\left(1-\tau_{L}\right)(1-\bar{b})+m n \ell S_{w}}{\left(1-\tau_{L}\right)(1-\bar{b})}>0$ and $F_{2}=\frac{-m\left[S_{r} q n \ell+(\pi+T) / h\right]}{\left(1-\tau_{L}\right)(1-\bar{b})}<0$.

\subsection{Concavity of Household and Firm Value Functions}

The concavity of the value function $\Gamma\left(n_{t}\right)$ in firm's optimization is easily confirmed as:

$$
\frac{\partial^{2} \Gamma\left(n_{t}\right)}{\partial\left(n_{t}\right)^{2}}=\alpha(1-\alpha) A\left(q_{t}^{F}\right)^{\alpha-1} q_{t+1}^{F}\left(n_{t}\right)+\frac{(1-\psi)^{2}}{1+\bar{r}} \Gamma_{n n}\left(n_{t+1}\right)<0
$$

The concavity of the value function $\Omega(\mathcal{H})$ in household's optimization is not as trivial, as it requires the Hessian matrix of $\Omega(\mathcal{H})$

$$
J^{\Omega} \equiv\left(\begin{array}{ccc}
\Omega_{k k} & \Omega_{k h} & \Omega_{k n} \\
\Omega_{h k} & \Omega_{h h} & \Omega_{h n} \\
\Omega_{n k} & \Omega_{n h} & \Omega_{n n}
\end{array}\right)
$$

to be negative semidefinite. We can easily show:

$\Omega_{k k}(\mathcal{H})=\frac{1-\delta_{k}+\left(1-\tau_{K_{t}}\right) r_{t}}{1+\rho}\left\{\Omega_{k k}\left(\mathcal{H}^{\prime}\right)\left[1-\delta_{k}+\left(1-\tau_{K t}\right) r_{t} s_{t}\right]+\Omega_{k h}\left(\mathcal{H}^{\prime}\right) \gamma\left(1-s_{t}\right) \widetilde{D}\left(q_{t}^{H}\right)^{\gamma-1}\right\}$

Under our parameterization in the benchmark model, $\Omega_{k k}(H)<0$.

By exhaustive manipulations, we have:

$$
\Omega_{h h}(\mathcal{H})=\frac{1}{1+\rho}(T E 1+T E 2+T E 3+T E 4)
$$

where

$$
\begin{aligned}
T E 1 & =\Omega_{k k}\left(\mathcal{H}^{\prime}\right)\left\{\left(1-\tau_{L_{t}}\right) w_{t}\left[n_{t} \ell_{t}+(1-n) \bar{b}_{t}\right]\right\}^{2}<0 \\
T E 2 & =\Omega_{h h}\left(\mathcal{H}^{\prime}\right)\left\{1+n_{t}\left(1-\ell_{t}\right)\left[D+\widetilde{D}(1-\gamma)\left(q_{t}^{H}\right)^{\gamma}\right]\right\}^{2}<0 \\
T E 3 & =\Omega_{h}\left(\mathcal{H}^{\prime}\right) n_{t}\left(1-\ell_{t}\right) \widetilde{D}(1-\gamma) \gamma\left(q_{t}^{H}\right)^{\gamma-1} q_{t+1}^{H}\left(h_{t}\right)<0 \\
T E 4 & =\left[\Omega_{k h}\left(\mathcal{H}^{\prime}\right)+\Omega_{h k}\left(\mathcal{H}^{\prime}\right)\right]\left(1-\tau_{L_{t}}\right) w_{t}\left[n_{t} \ell_{t}+\left(1-n_{t}\right) \bar{b}_{t}\right]\left\{1+n_{t}\left(1-\ell_{t}\right)\left[D+\widetilde{D}(1-\gamma)\left(q_{t}^{H}\right)^{\gamma}\right]\right\}>0
\end{aligned}
$$

Under our parameterization in the benchmark model, $\Omega_{h h}(\mathcal{H})<0$. Additional exhaustive manipulations yield:

$$
\Omega_{n n}(\mathcal{H})=\frac{1}{1+\rho}(T E 5+T E 6+T E 7+T E 8+T E 9+T E 10+T E 11)
$$


where

$$
\begin{aligned}
T E 5 & =\Omega_{k k}\left(\mathcal{H}^{\prime}\right)\left[\left(1-\tau_{L_{t}}\right) w_{t} h_{t}\left(\ell_{t}-\bar{b}_{t}\right)\right]^{2}<0 \\
T E 6 & =\Omega_{h h}\left(\mathcal{H}^{\prime}\right)\left\{\left(1-\ell_{t}\right) h_{t}\left[D+\widetilde{D}(1-\gamma)\left(q_{t}^{H}\right)^{\gamma}\right]\right\}^{2}<0 \\
T E 7 & =\Omega_{h}\left(\mathcal{H}^{\prime}\right)\left(1-\ell_{t}\right) h_{t} \widetilde{D}(1-\gamma) \gamma\left(q_{t}^{H}\right)^{\gamma-1} q_{t+1}^{H}\left(n_{t}\right)<0 \\
T E 8 & =\Omega_{n n}\left(\mathcal{H}^{\prime}\right)\left(1-\psi-\mu_{t}\right)^{2}<0 \\
T E 9 & =\left[\Omega_{k h}\left(\mathcal{H}^{\prime}\right)+\Omega_{h k}\left(\mathcal{H}^{\prime}\right]\left(1-\tau_{L_{t}}\right) w_{t} h_{t}\left(\ell_{t}-\bar{b}_{t}\right)\left(1-\ell_{t}\right) h_{t}\left[D+\widetilde{D}(1-\gamma)\left(q_{t}^{H}\right)^{\gamma}\right]>0\right. \\
T E 10 & =\left[\Omega_{k n}\left(\mathcal{H}^{\prime}\right)+\Omega_{n k}\left(\mathcal{H}^{\prime}\right)\right]\left(1-\tau_{L_{t}}\right) w_{t} h_{t}\left(\ell_{t}-\bar{b}_{t}\right)\left(1-\psi-\mu_{t}\right)>0 \\
T E 11 & =\left[\Omega_{h n}\left(\mathcal{H}^{\prime}\right)+\Omega_{n h}\left(\mathcal{H}^{\prime}\right)\right]\left(1-\ell_{t}\right) h_{t}\left[D+\widetilde{D}(1-\gamma)\left(q_{t}^{H}\right)^{\gamma}\right]\left(1-\psi-\mu_{t}\right)>0
\end{aligned}
$$

Under our parameterization in the benchmark model, $\Omega_{n n}(\mathcal{H})<0$. The $2 \times 2$ principal minors of $J^{\Omega}$ need be all positive and the determinant $\left|J^{\Omega}\right|$ need be negative, which are too complicated to identify clean sufficient conditions; nonetheless, they all hold true under our calibrated benchmark parametrization.

\subsection{Quasi-Social Planner's Optimization}

The quasi-social planner's problem is given by,

$$
\Lambda\left(k_{t}, h_{t}, n_{t}\right)=\max _{c_{t}, \ell_{t}, s_{t}, v_{t}} U\left(c_{t}\right)+m\left(1-n_{t}\right)+\frac{1}{1+\rho} \Lambda\left(k_{t+1}, h_{t+1}, n_{t+1}\right)
$$

subject to:

$$
\begin{gathered}
k_{t+1}=A\left(s_{t} k_{t}\right)^{\alpha}\left(n_{t} \ell_{t} h_{t}\right)^{1-\alpha}-\phi \bar{y}_{t} v_{t}-c_{t} \\
h_{t+1}-h_{t}=D n_{t}\left(1-\ell_{t}\right) h_{t}+\widetilde{D}\left[\left(1-s_{t}\right) k_{t}\right]^{\gamma}\left[n_{t}\left(1-\ell_{t}\right) h_{t}\right]^{1-\gamma} \\
n_{t+1}=(1-\psi) n_{t}+B\left(1-n_{t}\right)^{\beta}\left(v_{t}\right)^{1-\beta}
\end{gathered}
$$

It is noted that while the resource constraint is straightforward by replacing income with net output and the human capital accumulation equation is identical to the decentralized problem, the evolution equations of employment differs from the decentralized program now with coordinated labor matches.

The quasi-social planner's optimization satisfies the following first-order conditions (with respect to $\left\{c_{t}, \ell_{t}, s_{t}, v_{t}\right\}$ ),

$$
\begin{aligned}
U_{c} & =\frac{1}{1+\rho} \Lambda_{k}\left(\mathcal{H}^{\prime}\right) \\
\Lambda_{k}\left(\mathcal{H}^{\prime}\right) A(1-\alpha)\left(q_{t}^{F}\right)^{\alpha} & =\Lambda_{h}\left(\mathcal{H}^{\prime}\right)\left[D+\widetilde{D}(1-\gamma)\left(q_{t}^{H}\right)^{\gamma}\right] \\
\Lambda_{k}\left(\mathcal{H}^{\prime}\right) A \alpha\left(q_{t}^{F}\right)^{\alpha-1} & =\Lambda_{h}\left(\mathcal{H}^{\prime}\right) \widetilde{D} \gamma\left(q_{t}^{H}\right)^{\gamma-1} \\
\Lambda_{k}\left(\mathcal{H}^{\prime}\right) \phi A\left(q_{t}^{F}\right)^{\alpha} n_{t} \ell_{t} h_{t} & =\Lambda_{n}\left(\mathcal{H}^{\prime}\right)(1-\beta) B\left(1-n_{t}\right)^{\beta}\left(v_{t}\right)^{-\beta}
\end{aligned}
$$


together with the respective Benveniste-Scheinkman conditions (associated with $\left\{k_{t}, h_{t}, n_{t}\right\}$ ):

$$
\begin{aligned}
\Lambda_{k}(\mathcal{H})= & \frac{1}{1+\rho} \Lambda_{k}\left(\mathcal{H}^{\prime}\right)\left[1-\delta_{k}+A \alpha\left(q_{t}^{F}\right)^{\alpha-1}\right] \\
\Lambda_{h}(\mathcal{H})= & \frac{1}{1+\rho}\left(\Lambda_{k}\left(\mathcal{H}^{\prime}\right) A(1-\alpha)\left(q_{t}^{F}\right)^{\alpha} n_{t} \ell_{t}+\Lambda_{h}\left(\mathcal{H}^{\prime}\right)\left\{1+n_{t}\left(1-\ell_{t}\right)\left[D+\widetilde{D}(1-\gamma)\left(q_{t}^{H}\right)^{\gamma}\right](\mathcal{H} 55)\right.\right. \\
\Lambda_{n}(\mathcal{H})= & -m+\frac{1}{1+\rho}\left\{\Lambda_{k}\left(\mathcal{H}^{\prime}\right) A(1-\alpha)\left(q_{t}^{F}\right)^{\alpha} \ell_{t} h_{t}+\Lambda_{h}\left(\mathcal{H}^{\prime}\right)\left(1-\ell_{t}\right) h_{t}\left[D+\widetilde{D}(1-\gamma)\left(q_{t}^{H}\right)^{\gamma}[46)\right.\right. \\
& \left.+\Lambda_{n}\left(\mathcal{H}^{\prime}\right)\left(1-\psi-\beta B\left(1-n_{t}\right)^{\beta-1}\left(v_{t}\right)^{1-\beta}\right)\right\}
\end{aligned}
$$

\subsection{Equilibrium}

We derive algebra in Section 3.Under the logarithmic utility function: $U(c)=\ln c$, households' lifetime utility is always bounded along a BGP. Moreover, $\Gamma_{n}\left(n^{\prime}\right)$ and $\Omega_{n}\left(\mathcal{H}^{\prime}\right)$ are constant along a BGP, whereas $\Omega_{k}\left(\mathcal{H}^{\prime}\right)$ and $\Omega_{h}\left(\mathcal{H}^{\prime}\right)$ are decreasing at rate $g$. Then, we use (6), (8), and (9) to derive a standard Keynes-Ramsey relationship governing consumption growth and an intertemporal optimization condition governing human capital accumulation as follows.

$$
\begin{gathered}
g=\frac{\left(1-\tau_{K}\right) r-\delta_{k}-\rho}{1+\rho} \\
\rho+(1+\rho) g=\left[D+\widetilde{D}(1-\gamma)\left(q^{H}\right)^{\gamma}\right][n+(1-n) \bar{b}]
\end{gathered}
$$

From the definition of $\pi$ and (16), we can derive the flow profit redistribution to each household in effective units as follows.

$$
\frac{\pi}{h}=n \ell\left\{A\left(q^{F}\right)^{\alpha}[(1-\alpha)-\phi v]-w\right\}
$$

From (3), the definition of $q^{F}$ and the flow profit redistribution given above, we can derive effective consumption along a BGP as:

$$
\begin{aligned}
\frac{c}{h} & =\left(S_{w} w+S_{r} q^{F}\right) n \ell+\frac{\pi}{h}+\frac{T}{h} \\
& =\left\{A\left(q^{F}\right)^{\alpha}[(1-\alpha)-\phi v]+S_{r} q^{F}-\left(1-S_{w}\right) w\right\} n \ell+\frac{T}{h}
\end{aligned}
$$

where $T$ is regarded as given by individuals with its equilibrium value being pinned down by the government budget constraint (21).

\subsection{Efficiency}

This Appendix derive algebra in Section 4. For the purpose of comparison, it is convenient to rewrite the conditions in Lemmas 1 and 2 in the decentralized problem 
as:

$$
\begin{aligned}
& \Omega_{k}\left(\mathcal{H}^{\prime}\right)=(1+\rho) U_{c} \\
& \Omega_{k}\left(\mathcal{H}^{\prime}\right)\left(1-\tau_{L_{t}}\right) w_{t}=\Omega_{h}\left(\mathcal{H}^{\prime}\right)\left[D+\widetilde{D}(1-\gamma)\left(q_{t}^{H}\right)^{\gamma}\right] \\
& \Omega_{k}\left(\mathcal{H}^{\prime}\right)\left(1-\tau_{K_{t}}\right) r_{t}=\Omega_{h}\left(\mathcal{H}^{\prime}\right) \widetilde{D} \gamma\left(q_{t}^{H}\right)^{\gamma-1} \\
&(1+\rho)\left(1+g_{t}\right)=\left[1-\delta_{k}+\left(1-\tau_{K_{t}}\right) r_{t}\right] \\
&(1+\rho)\left(1+g_{t}\right)-1=\left[D+\widetilde{D}(1-\gamma)\left(q_{t}^{H}\right)^{\gamma}\right]\left[n_{t}+\left(1-n_{t}\right) \bar{b}_{t}\right] \\
& \Omega_{n}=\frac{1+\rho}{\rho+\psi+\mu_{t}}\left[\left(1-\bar{b}_{t}\right)\left(1-\tau_{L_{t}}\right) w_{t} h_{t} U_{c}-m\right] \\
& \Gamma_{n}=\frac{1+R_{t}}{\psi+R_{t}}\left[(1-\alpha) A\left(q_{t}^{F}\right)^{\alpha}-w_{t}\right]
\end{aligned}
$$

We can then differentiate (52) and (53) to obtain:

$$
\begin{aligned}
d \Omega_{n} / d w_{t} & =\frac{1+\rho}{\rho+\psi+\mu_{t}}\left(1-\bar{b}_{t}\right)\left(1-\tau_{L_{t}}\right) h_{t} U_{c} \\
d \Gamma_{n} / d w_{t} & =-\frac{1+R_{t}}{\psi+R_{t}}
\end{aligned}
$$

The cooperative Nash wage bargaining therefore implies:

$$
\begin{aligned}
\Omega_{n} & =-\frac{\zeta}{1-\zeta} \frac{d \Omega_{n} / d w_{t}}{d \Gamma_{n} / d w_{t}} \Gamma_{n} \\
& =-\frac{\zeta}{1-\zeta} \frac{d \Omega_{n} / d w_{t}}{d \Gamma_{n} / d w_{t}} \frac{1+R_{t}}{\psi+R_{t}}\left[(1-\alpha) A\left(q_{t}^{F}\right)^{\alpha}-w_{t}\right]
\end{aligned}
$$

The above expression can be combined with (52) to yield:

$$
\begin{aligned}
(1+\rho)\left[\left(1-\bar{b}_{t}\right)\left(1-\tau_{L_{t}}\right) w_{t} h_{t} U_{c^{-}} m\right] & =-\frac{\zeta}{1-\zeta} \frac{d \Omega_{n} / d w_{t}}{d \Gamma_{n} / d w_{t}} \frac{\left(1+R_{t}\right)\left(\rho+\psi+\mu_{t}\right)}{\psi+R_{t}}\left[(1-\alpha) A\left(q_{t}^{F}\right)^{\alpha}-w_{t}\right] \\
& =\frac{\zeta}{1-\zeta}(1+\rho)\left(1-\bar{b}_{t}\right)\left(1-\tau_{L_{t}}\right) h_{t} U_{c}\left[(1-\alpha) A\left(q_{t}^{F}\right)^{\alpha}-w_{t}\right]
\end{aligned}
$$

which can be simplified to the decentralized labor-leisure-consumption trade-off as follows.

$$
\left(1-\bar{b}_{t}\right)\left(1-\tau_{L_{t}}\right) w_{t} h_{t} U_{c}-(1-\zeta) m=\zeta\left(1-\bar{b}_{t}\right)\left(1-\tau_{L_{t}}\right) h_{t}(1-\alpha) A\left(q_{t}^{F}\right)^{\alpha} U_{c}
$$


Concerning centralized solution, we rewrite the conditions in Lemma 5 to get:

$$
\begin{gathered}
\Lambda_{k}\left(\mathcal{H}^{\prime}\right)=(1+\rho) U_{c} \\
\Lambda_{k}\left(\mathcal{H}^{\prime}\right) A(1-\alpha)\left(q_{t}^{F}\right)^{\alpha}=\Lambda_{h}\left(\mathcal{H}^{\prime}\right)\left[D+\widetilde{D}(1-\gamma)\left(q_{t}^{H}\right)^{\gamma}\right] \\
\Lambda_{k}\left(\mathcal{H}^{\prime}\right) A \alpha\left(q_{t}^{F}\right)^{\alpha-1}=\Lambda_{h}\left(\mathcal{H}^{\prime}\right) \widetilde{D} \gamma\left(q_{t}^{H}\right)^{\gamma-1} \\
\Lambda_{k}\left(\mathcal{H}^{\prime}\right) \phi A\left(q_{t}^{F}\right)^{\alpha} n_{t} \ell_{t} h_{t}=\Lambda_{n}\left(\mathcal{H}^{\prime}\right)(1-\beta) B\left(1-n_{t}\right)^{\beta}\left(v_{t}\right)^{-\beta} \\
(1+\rho)\left(1+g_{t}\right)=\left[1-\delta_{k}+A \alpha\left(q_{t}^{F}\right)^{\alpha-1}\right] \\
(1+\rho)\left(1+g_{t}\right)-1=\left[D+\widetilde{D}(1-\gamma)\left(q_{t}^{H}\right)^{\gamma}\right] n_{t} \\
{\left[\rho+\psi+\beta B\left(1-n_{t}\right)^{\beta-1}\left(v_{t}\right)^{1-\beta}\right] \Lambda_{n}=(1+\rho)\left[A(1-\alpha)\left(q_{t}^{F}\right)^{\alpha} h_{t} U_{c}-m\right]} \\
(1-\beta) B\left(1-n_{t}\right)^{\beta}\left(v_{t}\right)^{-\beta} \Lambda_{n}=\phi A\left(q_{t}^{F}\right)^{\alpha} n_{t} \ell_{t} h_{t}(1+\rho) U_{c}
\end{gathered}
$$

where the last two expressions can be combined with $\psi n_{t}=\mu_{t}\left(1-n_{t}\right)=\eta_{t} v_{t}=$ $B\left(1-n_{t}\right)^{\beta}\left(v_{t}\right)^{1-\beta}$ to yield:

$$
\begin{aligned}
A(1-\alpha)\left(q_{t}^{F}\right)^{\alpha} h_{t} U_{c}-m & =\frac{\rho+\psi+\beta B\left(1-n_{t}\right)^{\beta-1}\left(v_{t}\right)^{1-\beta}}{(1-\beta) B\left(1-n_{t}\right)^{\beta}\left(v_{t}\right)^{-\beta}} \phi A\left(q_{t}^{F}\right)^{\alpha} n_{t} \ell_{t} h_{t} U_{c} \\
& =\frac{\rho+\psi+\beta \mu_{t}}{(1-\beta) \eta_{t}} \phi A\left(q_{t}^{F}\right)^{\alpha} n_{t} \ell_{t} h_{t} U_{c}
\end{aligned}
$$

which can be simplified to the counterpart of this labor-leisure-consumption trade-off under the centralized solution as follows.

$$
(1-\alpha) A\left(q_{t}^{F}\right)^{\alpha} h_{t} U_{c}-\frac{\rho+\psi+\beta \mu_{t}}{\eta_{t} v_{t}} \Phi U_{c}-(1-\beta) m=\beta(1-\alpha) A\left(q_{t}^{F}\right)^{\alpha} h_{t} U_{c}
$$

where $\Phi=\phi v_{t} \bar{y}_{t}=\phi v_{t} A\left(q_{t}^{F}\right)^{\alpha} n_{t} \ell_{t} h_{t}$ is the vacancy creation cost.

Then, by comparing the decentralized and centralized solutions, namely (51) and (55), we can identify four conditions in a more straightforward manner:

$$
\begin{aligned}
R_{t} & =r_{t} \\
\Omega_{k}\left(\mathcal{H}^{\prime}\right) & =\Lambda_{k}\left(\mathcal{H}^{\prime}\right) \\
\tau_{K_{t}} & =0 \\
\bar{b}_{t} & =0
\end{aligned}
$$

Moreover, to ensure the labor-leisure-consumption trade-off under decentralization and centralization to be identical, we need to establish equivalence between the decentralized labor-leisure-consumption trade-off and the counterpart of this labor-leisure- 
consumption trade-off under the centralized solution, which holds true under the following conditions:

$$
\begin{aligned}
\zeta & =\beta \\
\tau_{L_{t}} & =0 \\
w_{t} & =\left(1-\Delta_{t}^{*}\right)(1-\alpha) A\left(q_{t}^{F}\right)^{\alpha}
\end{aligned}
$$

where efficient wage discount $\Delta_{t}^{*}$ is given by,

$$
\Delta_{t}^{*}=\frac{\left(\rho+\psi+\beta \mu_{t}\right) \phi v_{t} \ell_{t}}{\psi(1-\alpha)}=\frac{\left(\rho+\psi+\beta \mu_{t}\right) \phi n_{t} \ell_{t}}{(1-\alpha) \eta_{t}}
$$

\subsection{Dynamic Taxation and Dynamic Tax Incidence}

This Appendix derives dynamic taxation. In deriving dynamic taxation, we maintain a BGP equilibrium with stationary matching and bargaining. This implies that $g$ and $n$ are constant. Then (22)), (23), (24), and (25) indicate that $\mu, \eta, v$, and $\theta$ are constant.

From (47), we derive:

$$
r_{t}=r\left(\tau_{K t}\right)=\frac{1}{1-\tau_{K t}}\left[g(1+\rho)+\delta_{k}+\rho\right]
$$

implying $r^{\prime}\left(\tau_{K t}\right)=\frac{1}{\left(1-\tau_{K t}\right)^{2}}\left[g(1+\rho)+\delta_{k}+\rho\right]>0$ and $r^{\prime \prime}\left(\tau_{K t}\right)=\frac{2}{\left(1-\tau_{K t}\right)^{3}}[g(1+\rho)+$ $\left.\delta_{k}+\rho\right]>0$.

From (48), we derive:

$$
q_{t}^{H}=q^{H}\left(\bar{b}_{t}\right)=\left\{\frac{1}{\widetilde{D}(1-\gamma)}\left[\frac{\rho+(1+\rho) g}{n+(1-n) \bar{b}_{t}}-D\right]\right\}^{\frac{1}{\gamma}}
$$

implying $\frac{\partial q_{t}^{H}}{\partial b_{t}}<0$. Moreover, $\frac{\partial q_{t}^{H}}{\partial g}>0$ and $\frac{\partial q_{t}^{H}}{\partial n}<0$.

From (26), we derive:

$$
\ell_{t}=\ell\left(\bar{b}_{t}\right)=1-\frac{g}{n\left\{D+\widetilde{D}\left[q^{H}\left(\bar{b}_{t}\right)\right]^{\gamma}\right\}}
$$

implying $\ell^{\prime}\left(\bar{b}_{t}\right)<0$. Moreover, $\frac{\partial \ell_{t}}{\partial g}<0$ and $\frac{\partial \ell_{t}}{\partial n}>0$.

From (16), we derive:

$$
R_{t}=R\left(\tau_{K t}\right)=r\left(\tau_{K t}\right)
$$

From (18), we derive:

$$
q_{t}^{F}=q^{F}\left(\tau_{K t}\right)=\left(\frac{\alpha A}{r\left(\tau_{K t}\right)}\right)^{\frac{1}{1-\alpha}}
$$

implying $\frac{\partial q_{t}^{F}}{\partial \tau_{K t}}=-\frac{1}{1-\alpha}\left(\frac{\alpha A}{r\left(\tau_{K t}\right)}\right)^{\frac{1}{1-\alpha}-1} r^{\prime}\left(\tau_{K t}\right)<0$. 
From (47) and (31), we derive:

$$
w_{t}=w\left(\tau_{K t}\right)=\left(\frac{\alpha^{\alpha} A}{r\left(\tau_{K t}\right)^{\alpha}}\right)^{\frac{1}{1-\alpha}}\left[1-\alpha-\frac{\left(r\left(\tau_{K t}\right)+\psi\right) \phi}{\eta(n)} n\right]
$$

implying $w^{\prime}\left(\tau_{K t}\right)=-\left(\alpha^{\alpha} A\right)^{\frac{1}{1-\alpha}} r^{\prime}\left(\tau_{K t}\right)\left\{\frac{\alpha r\left(\tau_{K t}\right)^{\frac{-1}{1-\alpha}}}{1-\alpha} \frac{\eta(n)(1-\alpha)-\left(r\left(\tau_{K t}\right)+\psi\right) \phi n}{\eta(n)}+\frac{\phi n r\left(\tau_{K t}\right)^{\frac{-\alpha}{1-\alpha}}}{\eta(n)}\right\}<$ 0 . Although $w^{\prime \prime}\left(\tau_{K t}\right)$ may be ambiguous, as a result of factor substitution, when the direct production cost effect dominates the labor market friction effect (the last term in the square bracket of the effective wage expression), effective wage is strictly concave in the capital tax rate and thus, $w^{\prime \prime}\left(\tau_{K t}\right)<0$.

Equation (11) becomes:

$$
\left(q^{H}\left(\bar{b}_{t}\right)\right)^{1-\gamma}\left[D+\widetilde{D}(1-\gamma)\left(q^{H}\left(\bar{b}_{t}\right)\right)^{\gamma}\right]=\widetilde{D} \gamma \frac{\left(1-\tau_{L_{t}}\right) w\left(\tau_{K t}\right)}{\left(1-\tau_{K_{t}}\right) r\left(\tau_{K t}\right)}
$$

from which we can express $\bar{b}_{t}$ as an equation of $\tau_{K t}$ and $\tau_{L t}$ :

$$
\bar{b}_{t}=\bar{b}\left(\tau_{K t}, \tau_{L t}\right)
$$

implying $\frac{\partial \bar{b}_{t}}{\partial \tau_{L t}}>0$. Moreover, $\frac{\partial \bar{b}_{t}}{\partial \tau_{K t}}>0$, because from $(47),\left(1-\tau_{K_{t}}\right) r\left(\tau_{K t}\right)$ is dependent on $\tau_{K t}$ only through its BGP effect on $g$, which we have already proved. Thus, the time varying effect of $\tau_{K t}$ only affect $w\left(\tau_{K t}\right)$ negatively, so $\tau_{K t}$ also affects $\bar{b}_{t}$ positively. This is the IR locus.

The IR locus is negatively sloping in the $\left(\tau_{L t}, \tau_{K t}\right)$ plane.

$$
\frac{d \tau_{L_{t}}}{d \tau_{K t}}=\frac{w^{\prime}\left(\tau_{K t}\right)\left(1-\tau_{L_{t}}\right)}{\frac{w\left(\tau_{K t}\right)}{\left(1-\tau_{K_{t}}\right) r\left(\tau_{K t}\right)}}=\frac{w^{\prime}\left(\tau_{K t}\right)\left(1-\tau_{L_{t}}\right)\left(1-\tau_{K_{t}}\right) r\left(\tau_{K t}\right)}{w\left(\tau_{K t}\right)}<0 .
$$

To see whether the isoquant is concave or convex, we take a second-order derivative to get

$$
\frac{d^{2} \tau_{L_{t}}}{d \tau_{K t}^{2}}=\frac{\left\{w\left(\tau_{K t}\right) w^{\prime \prime}\left(\tau_{K t}\right)-w^{\prime}\left(\tau_{K t}\right)^{2}\left[1+\left(1-\tau_{K_{t}}\right) r\left(\tau_{K t}\right)\right]\right\}\left(1-\tau_{L_{t}}\right)\left(1-\tau_{K_{t}}\right) r\left(\tau_{K t}\right)}{w\left(\tau_{K t}\right)^{2}}
$$

If $w^{\prime \prime}\left(\tau_{K t}\right)<0$, then $\frac{d^{2} \tau_{L_{t}}}{d \tau_{K t}^{2}}<0$ and the IR locus is concave to the origin. Our quantitative exercises confirm $w^{\prime \prime}\left(\tau_{K t}\right)<0$ and thus, the IR locus is concave to the origin.

In order to quantify time-varying factor taxes, we impose the following factor tax schedules

$$
\begin{aligned}
\tau_{K_{t}}-\tau_{K}^{*} & =A_{K} e^{-a_{K}(t) \cdot t} \\
\tau_{L_{t}}-\tau_{L}^{*} & =-A_{L} e^{-a_{L}(t) \cdot t}
\end{aligned}
$$


where $A_{K}, a_{K}(t), A_{L}, a_{L}(t)$ are coefficients that are to be calibrated. Below, we characterize these coefficients. First, from (47), we have $\left(1-\tau_{L_{t}}\right) w\left(\tau_{K t}\right)=g(1+\rho)+$ $\delta_{k}+\rho$ which is constant. Then we rewrite (11) as

$$
\left(q^{H}\left(\bar{b}_{t}\right)\right)^{1-\gamma}\left[D+\widetilde{D}(1-\gamma)\left(q^{H}\left(\bar{b}_{t}\right)\right)^{\gamma}\right]=\widetilde{D} \gamma \frac{\left(1-\tau_{L_{t}}\right) w\left(\tau_{K t}\right)}{g(1+\rho)+\delta_{k}+\rho}
$$

Next, using (31) to substitute $w\left(\tau_{K t}\right)$ in (11), we have

$$
\left(1-\tau_{L_{t}}\right)\left(\frac{\alpha^{\alpha} A}{r\left(\tau_{K t}\right)^{\alpha}}\right)^{\frac{1}{1-\alpha}}\left[1-\alpha-\frac{\phi n}{\eta}\left(r\left(\tau_{K t}\right)+\psi\right)\right]=\Theta
$$

where $\Theta=\left(q^{H}\left(\bar{b}_{t}\right)\right)^{1-\gamma}\left[D+\widetilde{D}(1-\gamma)\left(q^{H}\left(\bar{b}_{t}\right)\right)^{\gamma}\right] \frac{g(1+\rho)+\delta_{k}+\rho}{\widetilde{D} \gamma}$.

Using (47) to substitute $r\left(\tau_{K t}\right)$ in (11) gives

$$
\left(1-\tau_{L_{t}}\right)\left(\frac{g(1+\rho)+\delta_{k}+\rho}{1-\tau_{K t}}\right)^{\frac{-\alpha}{1-\alpha}}\left[1-\alpha-\frac{\phi n}{\eta}\left\{\frac{1}{1-\tau_{K t}}\left[g(1+\rho)+\delta_{k}+\rho\right]+\psi\right\}\right]=\left(\alpha^{\alpha} A\right)^{\frac{-1}{1-\alpha}} \Theta
$$

At $t=0$, the initial condition is $\tau_{K_{0}}=\tau_{K}^{*}+A_{K}$ and $\tau_{L_{0}}=\tau_{L}^{*}-A_{L}$. Then (11) at $t=0$ gives the relationship between $A_{L}$ and $A_{K}$ as follows.

$$
A_{L}\left(A_{K}\right)=-1+\tau_{L}^{*}+\frac{\left(\alpha^{\alpha} A\right)^{\frac{-1}{1-\alpha}}\left[\frac{g(1+\rho)+\delta_{k}+\rho}{1-\tau_{K}^{*}-A_{K}}\right]^{\frac{\alpha}{1-\alpha}} \Theta(\bar{b})}{1-\alpha-\frac{\phi n}{\eta}\left[\frac{g(1+\rho)+\delta_{k}+\rho}{1-\tau_{K}^{*}-A_{K}}+\psi\right]}
$$

which depends positively on $A_{K}$ when the capital income share is not too high such that $\alpha<\min \left\{\frac{1}{2}, 1-\frac{\psi \phi n}{\eta}\right\}$. Thus the two initial tax rates are negatively related, which is easily understood because the IR locus is downward sloping. Moreover, at time $t$, the speed of labor taxation $a_{L}(t)$ is governed by

$$
\begin{aligned}
\ln \left[1-\tau_{L}^{*}+A_{L}\left(A_{K}\right) e^{-a_{L}(t) \cdot t}\right]= & \ln \left(\alpha^{\alpha} A\right)^{\frac{-1}{1-\alpha}} \Theta(\bar{b})+\frac{\alpha}{1-\alpha} \ln \frac{g(1+\rho)+\delta_{k}+\rho}{1-\tau_{K}^{*}-A_{K} e^{-a_{K}(t) \cdot t}} \\
& -\ln \left\{1-\alpha-\frac{\phi n}{\eta}\left[\frac{g(1+\rho)+\delta_{k}+\rho}{1-\tau_{K}^{*}-A_{K} e^{-a_{K}(t) \cdot t}}+\psi\right]\right\}
\end{aligned}
$$

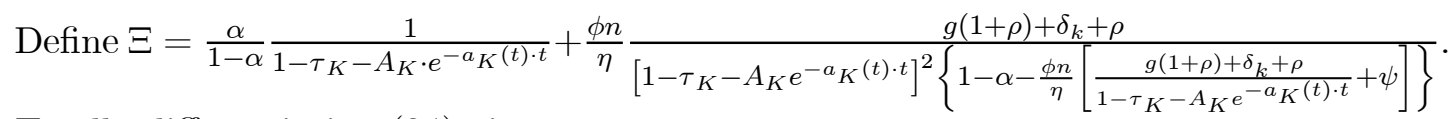

Totally differentiating (34) gives

$$
\frac{A_{L} t e^{-a_{L}(t) \cdot t}}{1-\tau_{L}+A_{L} e^{-a_{L}(t) \cdot t}} d a_{L}=\left\{\frac{A_{L}^{\prime}\left(A_{K}\right) e^{-a_{L}(t) \cdot t}}{1-\tau_{L}+A_{L} e^{-a_{L}(t) \cdot t}}-\Xi e^{-a_{K}(t) \cdot t}\right\} d A_{K}+\Xi A_{K} t e^{-a_{K}(t) \cdot t} d a_{K}
$$

Thus, $\frac{d a_{L}}{d a_{K}}>0$ whereas $\frac{d a_{L}}{d A_{K}}$ is ambiguous, but $\frac{d a_{L}}{d A_{K}}>0$ if the effect through $A_{L}$ dominates (which is the case of our calibrated economy). 
To evaluate the welfare, first we rewrite (2) as

$$
\frac{h_{t+1}}{h_{t}}=1+D n_{t}\left(1-\ell_{t}\right)+\widetilde{D}\left(q_{t}^{H}\right)^{\gamma} n_{t}\left(1-\ell_{t}\right)
$$

Since $n_{t}, q_{t}^{H}$ and $\ell_{t}$ are constant, then the growth rate of $h_{t}$ is constant. Since the growth rate of $h_{t}$ is constant, then we only need to analyze the transition of $\frac{c_{t}}{h_{t}}$ when evaluating welfare.

Then, from (27), we derive

$$
s_{t}=s\left(\tau_{K t}, \bar{b}\right)=\frac{q^{F}\left(\tau_{K t}\right) \ell\left(\bar{b}_{t}\right)}{[1-\ell(\bar{b})] q^{H}(\bar{b})+q^{F}\left(\tau_{K t}\right) \ell(\bar{b})}
$$

which is decreasing in $\tau_{K t}$.

Moreover, from (21), we have

$$
\frac{T_{t}}{h_{t}}=w\left(\tau_{K t}\right)\left\{\tau_{L t}[n \ell+(1-n) \bar{b}]-(1-n) \bar{b}\right\}+\tau_{K_{t}} r\left(\tau_{K t}\right) q^{F}\left(\tau_{K t}\right) n \ell
$$

which is increasing in $\tau_{L t}$ but the effect of $\tau_{K t}$ is complicated. Since $\tau_{K_{t}} r\left(\tau_{K t}\right) q^{F}\left(\tau_{K t}\right) \propto$ $\tau_{K_{t}}\left(1-\tau_{K_{t}}\right)^{\frac{\alpha}{1-\alpha}}$, straightforward differentiation implies $\tau_{K_{t}} r\left(\tau_{K t}\right) q^{F}\left(\tau_{K t}\right)$ is increasing in $\tau_{K_{t}}$ if $\tau_{K_{t}}<1-\alpha$. Yet, a higher $\tau_{K_{t}}$ lowers $w\left(\tau_{K t}\right)$, thus leading to an ambiguous result. In our calibrated economy, the indirect effect via $w\left(\tau_{K t}\right)$ is dominated by the direct effect. As a result, both factor tax rates raise effective lump-sum tax. Also note that $S_{w t}=S_{w}\left(\tau_{L t}, \bar{b}\right)=\left(1-\tau_{L t}\right)\left[1+\frac{(1-n) \bar{b}}{n \ell}\right]$ and $S_{r t}=S_{r}\left(\tau_{K t}, \bar{b}\right)=$ $\left[\left(1-\tau_{K t}\right) r\left(\tau_{K t}\right)-\frac{g+\delta_{k}}{s\left(\tau_{K t}, b_{t}\right)}\right]$. While $S_{w t}$ is decreasing in $\tau_{L t}, S_{r t}$ is decreasing in $\tau_{K t}$.

Furthermore, from (50), we have

$\frac{c_{t}}{h_{t}}=\left\{A\left(q^{F}\left(\tau_{K t}\right)\right)^{\alpha}[(1-\alpha)-\phi v]+S_{r}\left(\tau_{K t}, \bar{b}\right) q^{F}\left(\tau_{K t}\right)-\left(1-S_{w}\left(\tau_{L t}, \bar{b}_{t}\right)\right) w\left(\tau_{K t}\right)\right\} n \ell+\frac{T_{t}}{h_{t}}$

Finally, we are ready to calibrate tax schedules. The calibration is carried out in the following steps.

(1) We set $A_{K}$ so to match the (given) initial $\tau_{K 0}$;

(2) Given $A_{K}$, the value of $a_{K}$ is set so that the difference between $\tau_{K_{t}}$ and $\tau_{K}^{*}$ (the optimal capital tax rate, $16.11 \%$ ) is within $1 \%$ of $\tau_{K}^{*}$ in the 50 th period;

(3) Then $A_{L}$ is set so that (11) is satisfied at the 10th period $(t=9)$;

(4) The value of $a_{L}$ is set so that the difference between $\tau_{L_{t}}$ and $\tau_{L}^{*}$ (the optimal capital labor rate, $24.09 \%$ ) is within $1 \%$ of $\tau_{L}^{*}$ at the 50 th period.

\subsection{Alternative Model II: Linear Human Capital Accumulation}

In the case with a linear human capital accumulation process independent of market goods, the first-order condition of the household's optimization problem (5) is the same while (6) becomes:

$$
\Omega_{k}\left(\mathcal{H}^{\prime}\right)\left(1-\tau_{L_{t}}\right) w_{t}=\Omega_{h}\left(\mathcal{H}^{\prime}\right) D
$$


The Benveniste-Scheinkman conditions of the household's optimization problem are now:

$$
\begin{gathered}
\Omega_{k}(\mathcal{H})=\frac{1}{1+\rho} \Omega_{k}\left(\mathcal{H}^{\prime}\right)\left[\left(1-\delta_{k}\right)+\left(1-\tau_{K_{t}}\right) r_{t}\right] \\
\Omega_{h}(\mathcal{H})=\frac{1}{1+\rho}\left\{\Omega_{k}\left(\mathcal{H}^{\prime}\right)\left(1-\tau_{L_{t}}\right) w_{t}\left[n_{t} \ell_{t}+\left(1-n_{t}\right) \bar{b}_{t}\right]+\Omega_{h}\left(\mathcal{H}^{\prime}\right)\left[1+D n_{t}\left(1-\ell_{t}\right)\right]\right\} \\
\Omega_{n}(\mathcal{H})=-m+\frac{1}{1+\rho}\left[\Omega_{k}\left(\mathcal{H}^{\prime}\right)\left(\ell_{t}-\bar{b}_{t}\right)\left(1-\tau_{L_{t}}\right) w_{t} h_{t} v_{t}+\Omega_{h}\left(\mathcal{H}^{\prime}\right) D\left(1-\ell_{t}\right) h_{t}+\Omega_{n}\left(\mathcal{H}^{\prime}\right)\left(1-\psi-\mu_{t}\right)\right]
\end{gathered}
$$

The BGP equilibrium expressions follow by simply setting $\widetilde{D}=0$ and $s=1$.

\subsection{Alternative Model III: Walrasin Model}

We consider a Walrasian economy with $n=1$. Let $q_{t}^{H}=\frac{\left(1-s_{t}\right) k_{t}}{\left(1-\ell_{t}\right) h_{t}}$ and $q_{t}^{F}=\frac{s_{t} k_{t}}{\ell_{t} h_{t}}$. Then the firm's optimal decisions are:

$$
\begin{aligned}
\alpha A\left(q_{t}^{F}\right)^{\alpha-1} & =r_{t} \\
(1-\alpha) A\left(q_{t}^{F}\right)^{\alpha} & =w_{t}
\end{aligned}
$$

Combining these, we have:

$$
q_{t}^{F}=\frac{\alpha w_{t}}{(1-\alpha) r_{t}}
$$

The household faces the following budget constraint:

$$
k_{t+1}=\left(1-\tau_{L t}\right) w_{t} \ell_{t} h_{t}+\left[\left(1-\delta_{k}+\left(1-\tau_{K_{t}}\right) r_{t}\right] k_{t}-c_{t}+T_{t}\right.
$$

The main change is the Benveniste-Scheinkman condition with respect to $h_{t}$ :

$$
\Omega_{h}(\mathcal{H})=\frac{1}{1+\rho}\left\{\Omega_{k}\left(\mathcal{H}^{\prime}\right)\left(1-\tau_{L_{t}}\right) w_{t} \ell_{t}+\Omega_{h}\left(\mathcal{H}^{\prime}\right)\left[1+\left(1-\ell_{t}\right)\left[D+\widetilde{D}(1-\gamma)\left(q_{t}^{H}\right)^{\gamma}\right]\right]\right\}
$$

By imposing a $\log$ utility function $U(c)=\ln c$, we can derive the following equations along the BGP:

$$
\begin{gathered}
\rho+(1+\rho) g=\left[D+\widetilde{D}(1-\gamma)\left(q^{H}\right)^{\gamma}\right] \\
\ell=1-\frac{g}{D+\widetilde{D}\left(q^{H}\right)^{\gamma}}
\end{gathered}
$$

The Keynes-Ramsey relationship (47) and (11) remain unchanged. The effective consumption along a BGP becomes:

$$
\frac{c}{h}=\left(1-\tau_{L}\right) w \ell+\left[\left(1-\tau_{K}\right) r-\frac{g+\delta_{k}}{s}\right] q^{F} \ell+\frac{T}{h}
$$


Table 1: Benchmark Parameter Values and Calibration

\section{Benchmark Parameters and Observables}

per capita real economic growth rate

physical capital's depreciation rate

$g$

0.0045

time preference rate

$\delta_{k} \quad 0.0100$

tax rate on capital

0.0125

tax rate on income

$\tau_{K}$

0.2000

replacement ratio

$\tau L$

0.2000

capital's share

0.4200

physical capital-human capital ratio

0.2800

job separating rate

1.0000

job finding rate

vacancy-searching worker ratio

labor searcher's share in matching production

parameter of human capital accumulation

preference parameter of leisure

$\begin{array}{cc}\text { k/h } & 1.0000 \\ \psi & 0.0986 \\ \mu & 0.8336 \\ v / u & 1.0000 \\ \beta & 0.4000 \\ \gamma & 0.2500 \\ \varepsilon & 0.5000\end{array}$

\section{Calibration}

coefficient of goods technology

0.1648

coefficient of matching technology

0.8336

capital-output ratio

A

8.2790

consumption-human capital ratio

$k / y$

0.0598

effective flow profit redistribution

$c / h$

0.0159

transfer-human capital ratio

$\pi / h$

0.0103

fraction of physical capital devoted to goods production

$T / h$

0.9981

effective capital-labor ratio in the nonmarket sector

$S$

effective capital-labor ratio in the market sector

$q^{H}$

$q^{F}$

0.0079

coefficient of the cost of vacancy creation and management

1.5394

coefficient of human capital accumulation

3.6306

coefficient of human capital accumulation

$D$

0.0178

rate of return of capital

fraction of time devoted to employment

fraction of time devoted to work

leisure preference parameter augmented by the intensity of

0.8943

leisure enjoyment

bargaining share to the household

0.4000

vacancy creation

0.1057

employee recruitment rate

0.8336

wage

$\eta$

0.0380

wage discount

0.7161 
Table 2: Numerical Results $\left(\tau_{K}=20 \%, \tau_{L}=20 \%\right)$

\begin{tabular}{c|c|cc}
\hline Key Variables & Benchmark & $\tau_{K}$ increases & $\tau_{L}$ increases \\
\hline$g$ & $\mathbf{0 . 0 0 4 5 0 0}$ & -0.020797 & -0.008461 \\
$c / h$ & $\mathbf{0 . 0 5 9 7 7 1}$ & 0.008626 & 0.008231 \\
$k / h$ & $\mathbf{1 . 0 0 0 0 0 0}$ & -0.357480 & 0.002187 \\
$y / h$ & $\mathbf{0 . 1 2 0 5 5 2}$ & -0.103532 & 0.001378 \\
$s$ & $\mathbf{0 . 9 9 8 0 5 5}$ & -0.000407 & 0.000616 \\
$n$ & $\mathbf{0 . 8 9 4 2 5 9}$ & -0.008813 & -0.001134 \\
$1-n$ & $\mathbf{0 . 1 0 5 7 4 1}$ & 0.074383 & 0.009590 \\
$\boldsymbol{\ell}$ & $\mathbf{0 . 7 2 5 0 0 0}$ & 0.004200 & 0.001959 \\
$(1-\ell) n$ & $\mathbf{0 . 2 4 5 9 2 1}$ & -0.019891 & -0.006299 \\
$q^{H}$ & $\mathbf{0 . 0 0 7 9 0 8}$ & -0.129685 & -0.309929 \\
$q^{F}$ & $\mathbf{1 . 5 3 9 4 0 6}$ & -0.353275 & 0.001979 \\
$r$ & $\mathbf{0 . 0 3 3 8 2 0}$ & 0.254361 & -0.001425 \\
$\left(1-\tau_{K}\right) r$ & $\mathbf{0 . 0 2 7 0 5 6}$ & -0.003501 & -0.001425 \\
$w$ & $\mathbf{0 . 0 3 8 0 0 1}$ & -0.101448 & 0.022356 \\
$(1-\tau L) w$ & $\mathbf{0 . 0 3 0 4 0 1}$ & -0.101448 & -0.235506 \\
$\Delta$ & $\mathbf{0 . 7 1 6 1 4 8}$ & 0.001002 & -0.008648 \\
$\mu$ & $\mathbf{0 . 8 3 3 6 2 5}$ & -0.083196 & -0.010724 \\
$\eta$ & $\mathbf{0 . 8 3 3 6 2 5}$ & 0.055464 & 0.007150 \\
$\boldsymbol{N}$ & $\mathbf{0 . 1 0 5 7 4 1}$ & -0.064277 & -0.008284 \\
\hline
\end{tabular}

Note 1. Numbers reported are elasticities with respect to respective exogenous shift in tax rates.

2. $g$ : per capita real economic growth rate; $c / h$ : consumption-human capital ratio; $k / h$ : physical capital-human capital ratio; $k / y$ :output-human capital ratio; $s$ : fraction of physical capital devoted to goods production; $n$ : fraction of time devoted to employment; $\boldsymbol{l}$ : fraction of time devoted to work; $q^{H}$ : effective capital-labor ratio in the nonmarket sector; $q^{F}$ : effective capital-labor ratio in the market sector; $r$ : rate of return of capital; $\Delta$ : wage discount; $\mu$ : job finding rate; $\eta$ : employee recruitment rate; $v$ : vacancy creation. 
Table 3: Sensitivity Analysis

\begin{tabular}{|c|c|c|c|c|c|c|}
\hline & $\tau_{K}{ }^{*}$ & $\tau_{L}^{*}$ & $\left(g^{*}-g\right) / g$ & $\left(\Omega *_{-} \Omega\right) / \Omega$ & $\begin{array}{l}\text { Welfare gain in } \\
\text { consumption } \\
\text { equivalence }\end{array}$ & $\begin{array}{c}\text { Welfare loss in } \\
\text { consumption } \\
\text { equivalence if } \tau_{\mathrm{K}}=0\end{array}$ \\
\hline Benchmark & 16.11 & 24.09 & 0.2025 & 0.0158 & 0.0389 & 0.6490 \\
\hline$\beta=0.235$ & 10.12 & 30.28 & 1.0003 & 0.1166 & 0.2879 & 0.2881 \\
\hline$\beta=\zeta=0.40$ & 16.11 & 24.09 & 0.2025 & 0.0158 & 0.0389 & 0.6490 \\
\hline$\beta=0.54$ & 19.62 & 20.40 & 0.0102 & 0.0001 & 0.0003 & 0.8985 \\
\hline$\beta=0.72$ & 22.93 & 16.88 & -0.0145 & 0.0077 & 0.0190 & 1.1525 \\
\hline $\begin{array}{c}m=-0.064 * 0.5 \\
(-0.032)\end{array}$ & 9.34 & 30.47 & 0.4542 & 0.0966 & 0.2367 & 0.1672 \\
\hline $\begin{array}{c}m=-0.064 * 1.5 \\
(-0.096)\end{array}$ & 21.10 & 18.77 & -0.0652 & 0.0015 & 0.0037 & 1.3947 \\
\hline $\begin{array}{c}m=-0.064 * 2 \\
(-0.128)\end{array}$ & 25.01 & 14.03 & -0.3255 & 0.0350 & 0.0876 & 2.4131 \\
\hline$\theta=0.9$ & 32.78 & 1.23 & -0.9782 & 0.2617 & 0.6717 & 5.6679 \\
\hline$\theta=1.1$ & 2.25 & 35.00 & 0.7049 & 0.2927 & 0.7049 & 0.0109 \\
\hline $\begin{array}{c}\bar{b}=0.42 * 0.9 \\
(0.378)\end{array}$ & 16.21 & 24.04 & 0.2662 & 0.0148 & 0.0366 & 0.6497 \\
\hline $\begin{array}{c}\bar{b}= \\
0.42 * 1.1 \\
(0.462)\end{array}$ & 16.03 & 24.12 & 0.1368 & 0.0166 & 0.0410 & 0.6511 \\
\hline $\begin{aligned} \gamma= & 0.25 * 0.9 \\
& (0.225)\end{aligned}$ & 15.74 & 24.48 & 0.2176 & 0.0186 & 0.0459 & 0.6109 \\
\hline $\begin{aligned} \gamma= & 0.25 * 1.1 \\
& (0.275)\end{aligned}$ & 16.44 & 23.75 & 0.1886 & 0.0134 & 0.0329 & 0.6857 \\
\hline$k / h=0.5$ & 16.11 & 24.09 & 0.2025 & 0.0123 & 0.0389 & 0.6491 \\
\hline$k / h=2$ & 16.11 & 24.09 & 0.2025 & 0.0220 & 0.0389 & 0.6490 \\
\hline$\tau_{K}=35 \%, \tau_{L}=20 \%$ & 34.97 & 20.04 & 0.0030 & 0.0000 & 0.0000 & $\mathrm{~N} / \mathrm{A}$ \\
\hline$\tau_{K}=40 \%, \tau_{L}=36 \%$ & 42.75 & 32.08 & -0.3308 & 0.0254 & 0.0552 & $\mathrm{~N} / \mathrm{A}$ \\
\hline
\end{tabular}

Note 1: Numbers reported are in percentage.

2: $\quad g$ : per capita real economic growth rate; $\Omega$ : household's lifetime utility; $\beta$ : labor searcher's share in matching production; $m$ : leisure preference parameter augmented by the intensity of leisure enjoyment; $\theta$ : labor-market tightness; $\bar{b}$ : replacement ratio; $\gamma:$ parameter of human capital accumulation; $k / h$ : physical capital-human capital ratio; $\tau_{K}$ : tax rate on capital income; $\tau_{L}$ : tax rate on labor income. 
Table 4: Tax Incidence Analysis under Various Setups

\begin{tabular}{l|cccccc}
\hline & $\tau_{K}^{*}$ & $\tau^{*}$ & $\left(g^{*}-g\right) / g$ & $\left(\Omega^{*}-\Omega\right) / \Omega$ & $\begin{array}{c}\text { Welfare gain in } \\
\text { consumption } \\
\text { equivalence }\end{array}$ & $\begin{array}{c}\text { Welfare loss in } \\
\text { consumption } \\
\text { equivalence if } \tau K=0\end{array}$ \\
\hline Benchmark & $\mathbf{1 6 . 1 1}$ & $\mathbf{2 4 . 0 9}$ & $\mathbf{0 . 2 0 2 5}$ & $\mathbf{0 . 0 1 5 8}$ & $\mathbf{0 . 0 3 8 9}$ & $\mathbf{0 . 6 4 9 0}$ \\
\hline I. Inelastic leisure & 9.05 & 31.33 & 0.39929 & 0.0833 & 0.2049 & 0.1194 \\
II. Linear HC & 4.99 & 46.68 & 1.1434 & 0.5578 & 1.5407 & 0.3115 \\
III. Exogenous HC & 0.00 & 42.55 & $\mathrm{~N} / \mathrm{A}$ & 0.4809 & 1.1784 & 0.0000 \\
IV. Exog g\& endog HC & 16.19 & 24.01 & 0.1987 & 0.0158 & 0.0389 & 0.6490 \\
V. Walrasian & 0.00 & 27.51 & 5.4285 & 4.5347 & 10.3581 & 0.0000 \\
VI. Alterna Instrument & 15.96 & 24.05 & -0.0430 & 0.0179 & 0.0441 & 0.6793 \\
\hline
\end{tabular}

Note: Numbers reported are in percentage. 


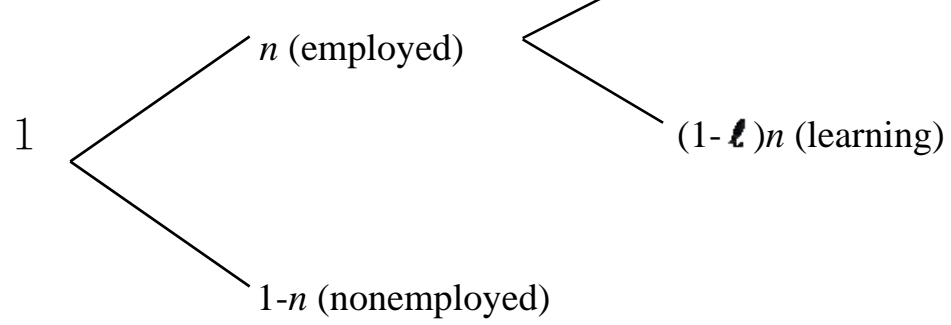

Figure 1: Labor Allocation by Households
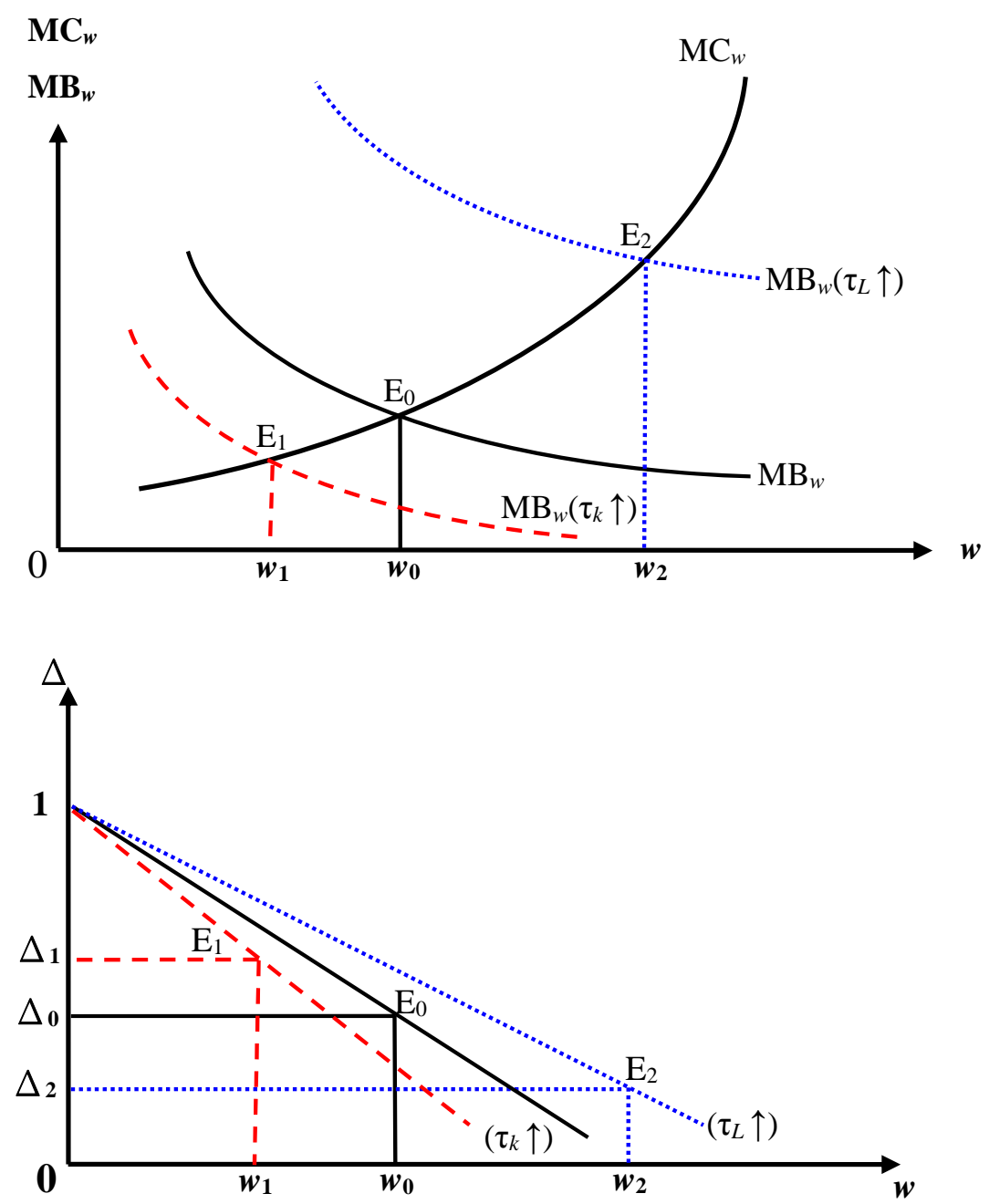

Figure 2: Effects of Factor Taxes on Wage Bargaining: Higher $\tau_{K}$ or $\tau_{L}$ 


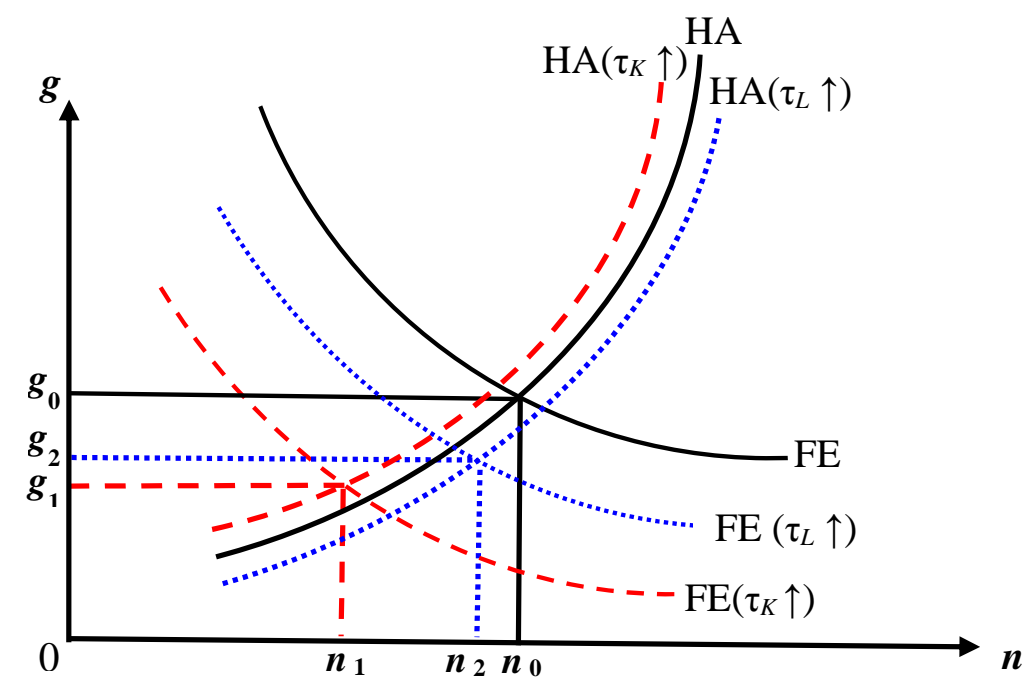

Figure 3: Growth Effects of Factor Taxes
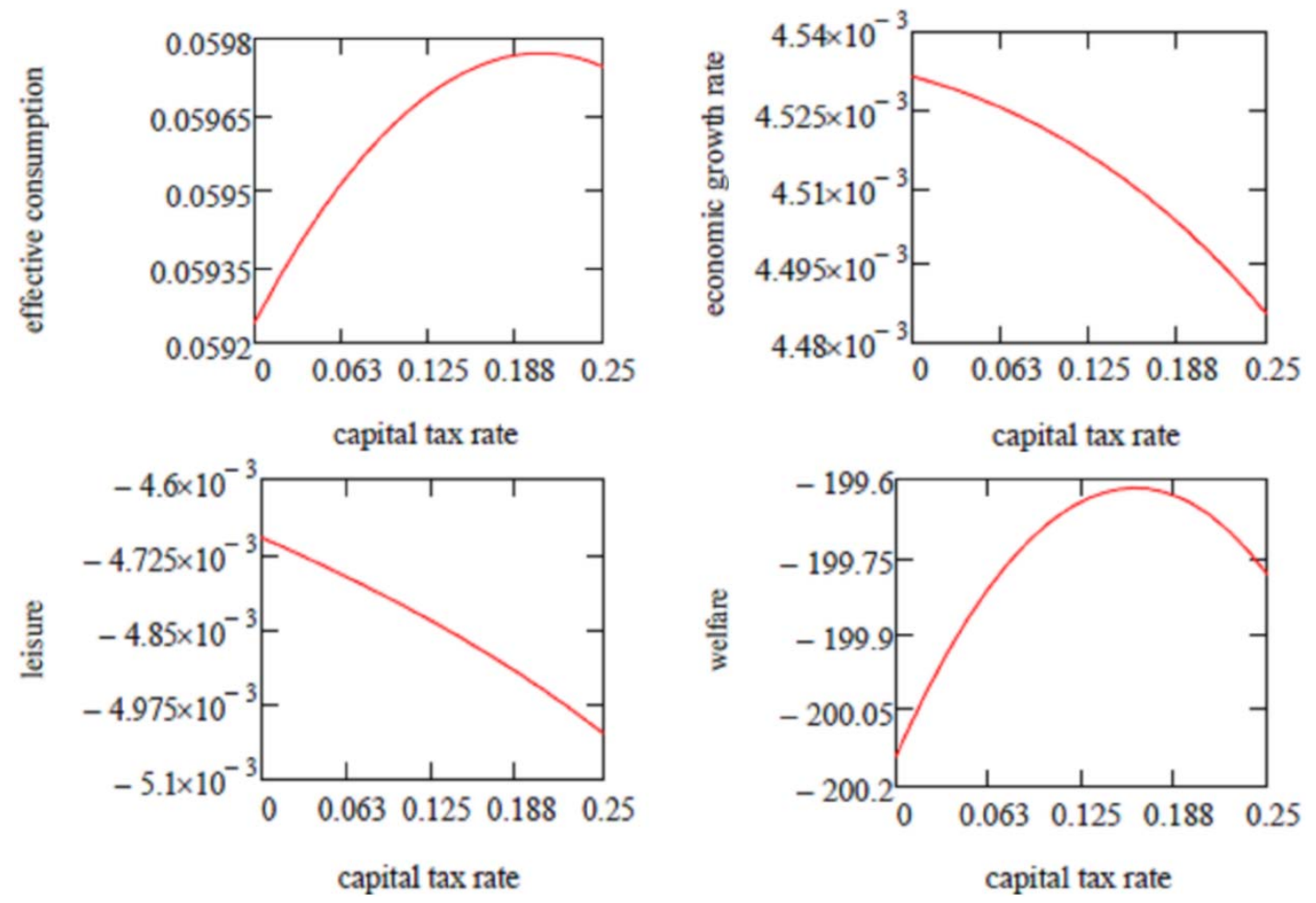

Figure 4: Dynamic Tax Incidence Results 